\title{
Mouse models of neurodegeneration: Know your question, know your mouse
}

\author{
Elizabeth M.C. Fisher ${ }^{1, *}$, David Bannerman ${ }^{2, *}$ \\ ${ }^{1}$ Department of Neuromuscular Disease, University College London, WC1N 3BG, UK \\ ${ }^{2}$ Department of Experimental Psychology, University of Oxford, Oxford, OX1 3TA, UK \\ ${ }^{*}$ Corresponding author. \\ E-mail: elizabeth.fisher@ucl.ac.uk (E.M.C.F.); David.Bannerman@psy.ox.ac.uk (D.B.)
}

Overline: Neurodegenerative Disease

\section{Single Sentence Summary:}

We can now create an unprecedented set of mouse models for understanding neurodegeneration and we need to carefully consider which model best fits our research question and how to learn from the variability within and between studies.

\begin{abstract}
Many mutant mouse strains have been developed to investigate neurodegenerative diseases, but variability among mouse studies has led to questioning of the value of these mouse models. Here, we appraise various mouse models for dissecting neurodegenerative mechanisms and emphasise the importance of asking appropriate scientific questions and understanding variability among and within studies. In therapeutics research, we suggest that not embracing this variability in mouse models may contribute to translational failure in human patients.
\end{abstract}

\section{INTRODUCTION}

Neurodegenerative diseases are common, largely untreatable and certainly incurable, and create a huge health and social burden worldwide. For example, in 2018, more than 50 million people worldwide had dementia of which $70 \%$ was caused by Alzheimer's disease (AD) with an overall cost of $\$ 1$ trillion(1). Currently $\sim 66 \%$ of those with dementia live in low or middle income countries (1). For neurodegenerative movement disorders, for example, 10 million people worldwide currently suffer from Parkinson's disease (PD) (2). These diseases are not necessarily illnesses of older age: type 1 
spinal muscular atrophy (SMA) is the biggest single genetic killer of children under 5 years of age, affecting up to 1 in 10,000 newborns. A typical mid-life onset disorder such as amyotrophic lateral sclerosis (ALS) has been described in children as young as 11 years of age (3). As with many other human diseases, each manifestation of neurodegeneration is likely to vary from person to person and will probably require a tailored combination of treatments for different patient subgroups.

For decades, mice have been the mammal of choice for modeling neurodegenerative diseases because of our ability to exquisitely manipulate their DNA. However, few genetically modified mouse models fully recapitulate the human condition or have yet been instrumental in delivering treatments for neurodegeneration. This is leading some researchers to doubt the utility of mouse models in the hunt for therapies and to turn instead to alternative approaches, such as induced pluripotent stem cells (iPSCs) derived from fibroblasts or other cells of patients. However, much of the uncertainty regarding mouse models stems from expecting each model to completely mimic human disease. Yet mice only live for two years or so and exhibit differences from humans at all levels, from the genome through to neuroanatomy, the immune system and behaviour. Uncertainty also arises from the apparent lack of reproducibility of results between laboratories. Indeed, confounding variability is evident not only across studies and across laboratories but also even within cohorts of the same genotype being studied within one laboratory.

Clearly, a multiplicity of models, including genetically modified mice and 3D cellular systems, is required to understand neurodegenerative diseases. For example, human iPSCs provide cellular models and robust in vitro readouts that could be used for high throughput analysis such as drug screens, which are not feasible in mice. However, mouse models remain essential because they enable us to take a holistic approach over the lifespan of an animal, giving us access to in vivo systemic interactions -- between cell types (for example, glia and neurons), tissues (for example, muscle and neurons), and whole animal systems (for example, the immune system and the nervous system). They also provide access to developmental, metabolic and behavioural outcomes over the natural history of a disease. In particular, as many of the symptoms in human patients we are trying to treat are behavioral (for example, memory impairments, deficits in cognition), it is essential to understand how molecular, cellular and circuit changes manifest as functional changes in the behavior of the organism. Mice also allow us to model environmental effects and individual responses over a lifetime in a way that is impossible in cellular systems.

Here, we argue that we need to acknowledge the differences between mice and humans and, most importantly, to tailor each mouse model to the research question being asked, in order to elucidate mechanisms of neurodegeneration. We ask why mice with the same genetic mutation have divergent phenotypes in pathological and behavioral sequelae and how we can turn this to our 
advantage. What we have hitherto seen as a problem and a lack of reproducibility, we now suggest may be an important opportunity for understanding gene interactions and interactions of genes with the environment, which may also underlie the variability of disease phenotypes observed in humans. Finally, we discuss briefly the failure to translate mechanistic findings in mice to therapies in humans, and suggest that this reflects the large diversity in the human clinical population that is currently not understood, nor captured in mouse studies. Embracing and understanding such variability in animal models may therefore be an essential step in the translational process.

\section{MICE AND HUMANS ARE DIFFERENT}

Despite the remarkable similarities between us, mice are not mini-humans and humans are not large mice. There are species-specific differences in every aspect of our biology, and these can be extremely helpful for highlighting key issues in human neurodegeneration.

At the genome level, $\sim 90 \%$ of mouse and human DNA falls into regions of conserved synteny, distributed between the 46 human chromosome pairs and the 40 mouse chromosome pairs. Both species have similar numbers of protein coding genes, but roughly $1 \%$ of mouse genes appear to have no human equivalent and vice versa (4). These genomic differences can be an issue for mouse models. For example, approximately 1 in 800 babies are born with trisomy of human chromosome 21 (Hsa21), resulting in Down's syndrome, which gives a greatly increased risk for early onset $A D(5)$. The long arm of Hsa21 has three regions of conserved homology with mouse chromosomes 10, 16, 17 (Mmu10, $16,17)$, and partial trisomies of these chromosomes have been used to model Down's syndrome (68) (6) (Figure 1). However, four Hsa21 protein-coding genes appear to be absent in the mouse genome, and at least four mouse genes found in the regions of homology seem absent in humans (9), so mouse partial trisomies cannot fully model human trisomy 21 . The Tc1 mouse model, which carries a partial copy of Hsa21, partly overcomes this issue, but human gene regulation and protein interactions may not be the same in a mouse cellular environment and this chromosome is lost stochastically from mouse cells (, for example, only 70\% of Tc1 mouse brain nuclei contain Hsa21) (7). No mouse can faithfully model Down's syndrome, but analysis of phenotypes across a variety of mouse models of this disease has been valuable for teasing apart the complex biology of this human chromosomal disorder, providing we take into account the characteristics of each model and ask specific questions about refined aspects of the syndrome that can be addressed in these models ( 6 , 10).

Gene copy number may differ between humans and mice. For example, humans have one copy of the SMN1 (survival motor neuron 1) gene and up to 4 copies of $S M N 2$, which are paralogs that 
lie within a duplicated region on chromosome 5. SMN2 has a single base pair difference from SMN1 that results in alternative splicing such that only up to $20 \%$ of SMN2 transcripts encode functional protein. Mutations in SMN1 result in SMA, a neurodegenerative disease in which the lower motor neurons gradually die, and the rate of death is inversely related to the amount of functional SMN2. In the most severe form of the disease, children die before the age of four. Mice have been essential for studying SMA, but the mouse has only one Smn gene. Heterozygous Smn mice carrying one knocked out allele and one wildtype allele are fully viable, whereas homozygous null mutant mice die early in embryogenesis (11). Importantly, SMA has been modeled successfully by placing human SMN2 into Smn null mice (11). Now, a range of genetically different SMA mouse models exists, each carrying different patient mutations. Alternatively, some SMA mouse models carry an Smn gene that is mutated to resemble human SMN2. Each model has different advantages and disadvantages, such as reduced disease severity but a longer time in which to study disease processes (11). These models, including conditional mutant mice, have helped to dissect the timing of neuronal loss and to identify which neuronal populations are at risk. Furthermore, these mouse models have been critical for the development of therapies both conventional and genetic $(11,12)$. These include the novel adenoassociated virus gene therapy approach, now with FDA approval for a Phase 2 clinical trial, and the antisense oligo drug Spinraza which in 2016 was approved by the FDA as the first therapy for SMA (13).

With respect to gene expression, the ENCODE project has examined regulatory regions of mouse and human genomes in multiple tissues and cell types, and has demonstrated transcript profiles of a large number of human and mouse genes. The ENCODE project has revealed that much of the cis-regulatory landscape, including DNAse1 hypersensitive sites, are different between the two species (14-17). Mouse and human also have different splice variants, and humans produce a greater number of splice isoforms (average of 3.4 isoforms per gene) compared to mice (2.4 isoforms per gene) (18). Splice isoform differences are particularly important in diseases such as the most common genetic form of frontotemporal dementia (FTD) (19), which is caused by mutations in the MAPT (microtubule-associated protein tau) gene that encodes the protein TAU. Transgenic mice have been made using human MAPT CDNAs and these have been helpful for pinning down mechanism but mostly cannot address the abnormalities found in FTD that are caused by aberrant TAU splice isoform ratios. Now, however, mice with the complete human MAPT genomic region exist and these animals carry the various human TAU splice variants. Importantly for developing therapies, such mice respond to antisense oligonucleotide treatment by switching isoforms, thus giving insight into tauopathies and new models for developing therapies for FTD (20). 
Non-protein coding DNA may, or may not, be well-conserved between human and mouse; for example, osteocrin is an activity dependent secreted factor that is induced by membrane depolorisation in human, but not mouse neurons - because a primate specific enhancer has repurposed the expression of this gene which is non-neuronal in mouse (21). Mouse non-coding RNAs largely diverge in sequence from those of humans (22). Mutations in non-coding regions can be causative for neurodegeneration. Examples include the intronic mutations arising from primate specific repeats in the TAF1 gene that results in X-linked Parkinsonism Dystonia or in the Fukutin gene that leads to Fukuyama muscular dystrophy in humans $(23,24)$ or the tRNA mutation that can lead to neurodegeneration in the cortex, cerebellum and hippocampus in mice (25). Cryptic or skiptic DNA elements may be associated with disease in humans but not exist in mice, such as the cryptic polyadenylation site in STATHMIN2 (a neuronal growth associated factor) that is present in sporadic and some genetic forms of ALS (26). Non-coding changes also modulate disease outcomes: for example, by 2017 more than 3,000 different genome-wide association studies (GWAS) had reported $>30,000$ SNP-disease associations, the vast majority of which lie in non-coding regions (27), indicating the importance of gene regulation in disease, including neurodegenerative disease $(25,28)$.

Surprisingly, small differences in human and mouse amino acid sequences can have large effects on phenotype. Humans with three copies of the wildtype APP gene encoding amyloid precursor protein succumb to early onset $A D$, whereas three copies of wildtype mouse App does not lead to similar amyloid deposition in mice (5). Human and mouse APP are highly homologous but the 17 amino acid differences between them include three key residues that affect how APP protein forms amyloid deposits, and this may in part explain why human and mouse respond differently to having three 'doses' of the wildtype APP gene (29). Studying these differences may help to shed light on how the primary amino acid sequence of APP affects amyloid deposition. Similarly, human and mouse superoxide dismutase 1 (SOD1) proteins have a few key amino acid differences, likely making the human protein more prone to aggregation than the mouse equivalent (30). The SOD1 ${ }^{D 83 G}$ mutation causes autosomal dominant ALS in humans, but in mice the picture is very different. A mouse with the identical nucleotide and amino acid mutation (Sod $1^{D 83 G}$ ) only exhibits progressive motor neuron loss when homozygous; such a mouse shows only mild upper motor neuron loss ( $20 \%$ by 29 weeks of age) and a similar loss (23\%) of lower motor neurons by 15 weeks of age. Remarkably, after these time points motor neuron loss stops and motor neuron numbers remain stable for at least a year, although accompanied by a severe peripheral neuropathy (31). Dissecting the phenotype of the $\operatorname{Sod} 1^{D 83 G}$ mouse has revealed that motor neuron axonal degeneration and cell body degeneration are separate phenomena (at least initially). Potentially, this provides insights into the human disorder SOD1-ALS 
and the separate loss-of-function and gain-of-function effects arising from a single mutation, even though the mouse does not fully model human ALS (31).

Cellular and metabolic pathways may be common to both species but may have a different importance in each. Mice lacking Hexa (hexosaminidase subunit alpha) were generated to model the lysosomal storage disorder Tay-Sachs disease, which in humans is caused by loss of HEXA function. In finding out why the null mouse does not overtly model this deadly childhood disorder, researchers teased out an alternative metabolic pathway that is present in mice but of less importance in humans, although it could nevertheless still be used as a possible therapeutic route for treating this disease (32). This highlights the important point that humans and mice have evolved to fill different niches and so major biochemical, metabolic and physiological pathways may be different between us. For example, compared to humans, mice have a higher specific metabolic rate (metabolic rate per gram of tissue) and, for example, larger deposits of brown fat that are essential for thermoregulation (33). Other differences include cell membranes that have more polyunsaturated fatty acids in mouse than in human (34); the different dietary requirements, for example, mice can synthesise vitamin C, whereas humans cannot (33); fundamental differences in the mouse and human immune systems (33) that must be taken into account as the connections between immunology and neurodegeneration are elucidated.

Genes themselves may be more important to one species than the other. For example, although we mostly share essential genes that are lethal if deleted, SOD1 is essential in humans but not in mice (35); Sod1 null mice survive, whereas no SOD1 null humans have been reported. This is important when modeling SOD1-ALS, as the majority of mutations result in some loss of superoxide dismutase 1 activity, which may have a more severe outcome in human motor neurons than in mouse motor neurons (36).

Differences in gross morphology are also important for our modeling of human disease, for example, size is closely correlated with metabolic rate in mammals (33). With respect to the gut and the microbiome, the relative length of the small intestine to the colon is larger in mice than in humans, probably because the cecum is important for microbial fermentation of foods in mice $(33,37)$. Mice and humans have clear neuroanatomical differences in the brain and spinal cord, although less so in the peripheral nervous system. In the brain, correspondence between human and mouse regions is largely characterised by histological staining patterns and the connections between regions, but there are many key differences. For example, the human brain has substantially more white matter than that of the mouse: the amount of white matter increases as a cubic function of the size of an animal because more axons are needed to innervate the body of larger animals (38). Also, some cell types 
found in the human brain have not been detected in the mouse brain (39). Furthermore, we are largely visual animals, whereas mice rely more heavily on other sensory inputs, such as olfaction.

Lifespan is another important difference when considering mouse models of mid-life/old-age neurodegenerative diseases. For example, the widely-used mouse strain C57BL/6J typically lives for just over two years, compared to, say, people in Japan who have an average (male and female combined) life expectancy of greater than 83 years. A mouse succumbing to disease at one year of age may be in late middle-age (depending on the strain), whereas at three months of age (often the age when mice are studied) that animal may be still a young adult. Moreover, aging in mice does not necessarily reflect the same processes as in humans (40).

For both humans and mice, we need to carefully tease apart the effects of normal aging from the effects of neurodegeneration. For example, this is an issue when investigating AD that arises in individuals with Down's syndrome, because premature aging is also part of the clinical picture of Down's syndrome (41). Moreover, a related point for mouse models is that individual inbred mouse lines may have alleles that predispose them to progressive phenotypes as the mice age, such as retinal degeneration, hearing loss, and other defects, even before any mutation is placed onto these strains (42). There are many apocryphal stories of researchers testing mice with visual cues, unaware that both littermate controls and mutant mice have vision loss. Therefore, we need to know about the normal aging characteristics of both mice and humans when investigating neurodegenerative phenotypes.

Undoubtedly one of the most difficult areas to tackle for neurodegeneration studies is that of behaviour. Nevertheless, although behavioural changes are highly variable among people affected by neurodegenerative diseases, there are common patterns such as memory loss or disinhibition, depending on the disorder. This is such a difficult area to appraise but is so important. 


\section{WHICH MUTATION, WHICH MOUSE MODEL?}

Whereas the majority of human neurodegenerative diseases are sporadic, meaning that we are all at risk (usually that risk increases with age), there are often rare familial monogenic forms of the disease that enable us to create animal models to study underlying mechanisms of pathogenesis. For example, up to $40 \%$ of FTD cases and $10 \%$ of ALS cases are due to mutations in single causative genes. Up to $5 \%$ of $A D$ is inherited in an autosomal dominant manner due to mutations in one of three genes $A P P$, presenilin 1 (PS1), and presenilin 2 (PS2). Approximately 15\% of PD occurs in people with a family history of the disease and up to $2 \%$ of all PD is due to causative (usually dominant) mutations in single genes. Causative alleles can vary greatly in different populations: the G2019S mutation in Leucine-rich repeat kinase 2 (LLRK2) accounts for $\sim 37 \%$ of familial PD in some Arab groups (43) but is rare in Taiwan (44). At the other end of the spectrum, nearly $100 \%$ of Huntington's disease (HD) arises from triplet repeat expansions in the HTT gene encoding the huntingtin protein.

Deciding which mutation to put into a mouse to model a specific neurodegenerative disease has often been a pragmatic choice of what is the fastest mutation to make, and what is likely to result in the most aggressive change found in humans, in order to have the best chance of producing a quantifiable phenotype in mouse. However, given the range of tools now available for genome engineering such as CRISPR/Cas, we can take a more considered approach to creating mouse models to answer specific questions about mechanism, without expecting a perfect mimic of human disease.

Here, we discuss the range of genetic mouse models available. Mouse models created using recombinant adeno-associated viral (AAV) or lentiviral vectors, for example, are also giving new insight into disease mechanisms for diseases such as $\operatorname{ALS}(45,46)$. This is a rapidly developing field that has implications for studying mechanisms of neurodegeneration as well as providing insights for downstream gene therapy approaches; (47). Another area that will be extremely important for dissecting neurodegenerative disease mechanisms is the increasing use of human-mouse chimeric animals, in which specific cell types are human and can be studied in vivo in the mouse [for example, as when wildtype human cells are studied within the environment of the brain in a mouse model of the amyloid deposition found in $A D(48)]$. This research platform brings its own challenges including ethical issues, and is a rapidly expanding area that we touch on only briefly below.

\section{Mouse modeling: What is the question?}

There are a few key questions that reoccur with all neurodegenerative diseases. For example, specific proteins are usually deposited in aggregates in the brain - but is protein deposition a disease causing mechanism or a disease response mechanism, or both? Why do neurons die? Causative genes are usually ubiquitously expressed, so why do only specific types of neurons or synapses die, usually in a 
well-described pattern? Does disease arise from loss-of-function or gain-of-function of the mutant protein, or both? What determines timing of symptom onset? Does a neuron die from mechanisms solely within that neuron ('cell autonomous') or do neighbouring cells play a role? How does the disease spread? What determines time to death? Why do these disorders progress from presymptomatic to symptomatic to end-stage? Why does incidence tend to increase with aging? What pathways produce variation in severity (and penetrance of genetic disease) and are these pathways routes to therapeutic modulation? What is the connection between histopathological changes and altered behavior? What is the therapeutic window? Is neurodegenerative disease reversible?

To help answer these questions we can now create mouse models to order, with exquisite accuracy (Figure 2). These include knockin models where the human mutation is engineered into the mouse genome, genomically humanized mouse models, transgenic mice, chemically mutagenized mice, conditional mutant mice, inducible mutant mice, chromosome engineered mutant models, and transchromosomal mutant models, each giving different types of information about neurodegenerative processes (Figure 2). In creating a mouse model of neurodegeneration, we therefore need to consider 'Which question are we trying to answer?' and then 'Which mouse model would best provide that answer?' The two big caveats that need to be considered as we ask these questions are: (1) mouse models are not predictable and we need to make the mouse to learn about the phenotypic outcome (2) the ultimate mouse phenotype depends on genetic background and environment.

For research into early neurodegenerative processes, mice expressing disease genes at physiological levels may provide slowly progressing, prodromal disease phenotypes that do not reach end-stage within the lifespan of a mouse. However, this may not be helpful for trying to test therapeutics targeted to later stages of the disease, which is often when patients first come to the clinic. Developing biomarkers or predictors of disease (for example, blood biochemicals, neuroimaging modalities, behavioral changes) may require access to nervous system and other tissues across disease stages, using different mouse models to address diagnostic issues and to monitor therapeutic outcomes. Endophenotypes (characteristics associated with a disorder but not necessarily a direct outcome of that disorder) may help with such issues but need careful validation. Mouse models can also indicate whether disease is reversible even at late stage (49) or whether treating non-neuronal tissue is helpful. For example, we think of SMA as a neurological deficit but therapies derived from studying a genetic mouse model of severe SMA, now target the liver because pre-clinical studies of liver pathology showed efficacy in this model (50).

The most widely used models of dominant neurodegenerative disease are still transgenic mice created by injecting DNA into the pronucleus of a fertilized mouse egg. The DNA inserts randomly, 
often creating additional unintended mutations such that multiple founder lines are required to exclude phenotypes arising from random insertion. The DNA also usually concatemerizes so the animal has multiple copies of the transgene and thus overexpresses the protein of interest. A study of 40 well-cited transgenic strains, many of which are used in neurodegeneration research, showed that about half had mutations at the insertion site, although little phenotypic outcome appears to be associated with these insertional mutation events (51). Injected constructs are often cDNAs under the control of non-endogenous promotors that are not expressed with the same pattern as the endogenous gene and are only expressed as the splice isoform encoded by the cDNA. Alternatively, Bacterial Artificial Chromosomes (BACs) may be injected into fertilized mouse eggs to create BAC transgenic mice. These have the following advantages. BACs have large insert sizes (up to $\sim 200 \mathrm{~kb}$ ) for genomic DNA that may include the entire promotor/exon/intron architecture of a single gene (or genes), thus, they may express the complete set of human splice isoforms. BACs also tend to integrate fewer than three copies hence ameliorating overexpression effects.

Transgenic mouse models expressing multiple copies of a mutant gene may show accelerated mid-life or late onset disease (if mutant protein levels and disease onset positively correlate), which is necessary for studying later stages of neurodegeneration. However, phenotypes may arise as a result of overexpression per se, rather than being caused by the effects of the mutation within the transgene DNA, as exemplified by the SOD $1^{G 93 A}$ transgenic model of ALS (52). Nevertheless, this ALS mouse strain is used to model human SOD1-ALS disease. This has allowed scientists access to an animal model of rapidly progressing disease and enabled study of later neurodegenerative processes. However, it is particularly important that strains like the $S O D 1^{G 93 A}$ transgenic mouse are compared to a transgenic mouse control overexpressing similar levels of the human wildtype protein, which in this case would be wildtype human SOD1 (53).

The utility of transgenic mice is exemplified by the field of prion disease research. Transgenic mice overexpressing a human prion protein were instrumental in showing that bovine spongiform encephalitis (BSE) could be transmitted between mammalian species (i.e. potentially to humans). Notably, had transgenic mice overexpressing the human prion protein not been used, this result would have been missed because the time course of the disease would have been longer than the lifespan of the mouse (54).

In terms of gene targeting, knockout mice have DNA sequences removed such that the targeted gene is no longer functional. These mice may be conditional or inducible such that the gene either loses function in response to genetic triggers (conditional) or can be inducibly expressed under experimental conditions through hormone or drug administration, either by injection or addition to the drinking water. In addition to understanding gene function, these animals can be extremely helpful 
for determining whether late stage neurodegeneration is reversible, by switching off the relevant gene mutation at specific time points (55).

Knockin mice have a sequence such as a mutation or mutant gene precisely targeted into their genome at a specific locus. Sequences may have exogenous promotors and can be placed into 'parking spots' or 'safe harbors', such as the Rosa26 locus, which are safe places to insert foreign DNA without disrupting other genes. DNA sequences may also be targeted by homologous recombination or by CRISPR/Cas9 and other technologies into their orthologous mouse locus, such that they are expressed at physiological levels by the mouse gene promoter. Because gene expression is therefore lower than in transgenic models, knockin mice tend to have longer times to disease onset and a slower, less aggressive course of disease, which may give researchers access to early disease stages. For example, a knockin mouse model of dominant ALS expresses the mutant protein VAPB (vesicle-associated membrane protein $\mathrm{B} / \mathrm{C}$ ) at physiological levels, and exhibits a much slower disease course than do transgenic animals overexpressing this protein (56). These knockin mice have dysfunctional motor neurons but no signs of motor neuron loss. Despite the lack of motor neuron death in this model, it gives us access to early disease processes and potentially to biomarkers, which are urgently needed for many human neurodegenerative diseases. Equally, mouse models of PD may not give the full human clinical picture, but can give access to the prodromal syndrome including behavioral abnormalities (57), although it can be difficult to tease out repair and compensation responses from true disease processes found in humans.

Knockin mouse models are particularly important if the gene of interest is dose-sensitive, i.e. more than the normal two copies gives rise to a phenotype that is not necessarily related to the disease under study. For example, point mutations in the FUS gene (fused in sarcoma) can cause ALS. As FUS is a dose-sensitive gene, transgenic FUS mice do not model FUS-ALS well, whereas knockin models expressing pathogenic FUS mutations at physiological levels are excellent models of ALS, giving access to early stage disease processes $(55,58)$. OtherALS genes such as C9orf72, or TARDBP which encodes the TDP-43 protein are also exquisitely dose sensitive $(56,59-62)$.

Another class of knockin mice are the genomically humanized models, in which either whole genes in the mouse genome are replaced with human genes $(63,64)$, or key mouse amino acid residues are targeted by knock in constructs and changed into human amino acids in the hope of producing more accurate phenotypes of human disease. These include the $A P P^{N L-F}$ and $A P P^{N L-F G}$ models of amyloid deposition (65) in which critical amino acids have been changed from mouse to human residues in the mouse APP protein, thus making amyloid- $\beta(A \beta)$ fragments generated from APP more prone to aggregation. 
Mutant mouse models can be generated with random mutations in the genome, such as those arising from chemical mutagenesis (66), which may give unexpected insights into gene dysfunction at physiological levels. For example, a chemically induced point mutation that turned out to be within the microRNA, miR-96, was shown to give rise to progressive hearing loss in mice (67) and this mutation was also found in humans with non-syndromic progressive hearing loss (68). Other types of mouse model include those created by chromosome engineering, which enables massive blocks of DNA to be moved around the genome or the deletion or duplication of big genomic regions. This allows us to model, for example, chromosomal full or partial aneuploidy $(6,69)$ or large-scale copy number variation (70).

A different type of model is provided by chimeric mice, which are made from two different cell lines and can be extremely helpful in dissecting cell autonomous and non-autonomous processes. For example, human pluripotent stem cell-derived cortical neuronal precursor cells derived from unaffected individuals have been transplanted into the brain of both a mouse model of $A D$ and wildtype animals. Notably, only the human neurons in the $A D$ mice showed signs of neurodegeneration indicating that that human neurons respond to $A \beta$ pathology differently from mouse neurons, in vivo, and the neurodegeneration is non-cell autonomous; the authors also showed neuronal death due to $A \beta$ deposition can be dissociated from tau tangle formation (48). In another example, chimeric mice with motor neurons expressing either wildtype or mutant SOD1 (causative for ALS) provided strong evidence that ALS is a non-cell autonomous disorder (71). Somatic mutation in which DNA changes in non-germ cells, such as neurons, are causal for neurodegeneration, can be modelled by conventional transgenic mice (72), andother types of mice with mosaic expression of key genes (73). It is likely that the use of chimeric mice to model neurodegeneration, for example, mice with a human immune system or specific human neurons, will increase greatly in the future.

Another advantage of working with mouse models to understand neurodegeneration is the ability to cross independent models and to study the double mutant progeny to tease out disease networks. Examples include a recent study of demyelinating and axonal neuropathy with specific genes that modify these phenotypes in mouse models of Charcot-Marie-Tooth disease (74), and a study of the effects of ApoE4 on tau-mediated neurodegeneration (75), and a study crossing a model of amyloid deposition and one of Down syndrome to try to determine why Down syndrome gives rise to early onset $A D(76)$. Similarly, such classical genetic crosses allow the uncovering of new genetic interactions, such as that between mutant SOD1 in ALS models and the cytoplasmic dynein heavy chain (77-79).

Clearly, one single mouse model for any given disease is unlikely to provide all of the outcomes needed to understand both the underlying early-stage and late-stage molecular mechanisms and to 
develop therapies and biomarkers. We need a tailored range of different animal models to address different questions about disease pathogenesis and treatment, and fortunately we are now in a position to produce the mice we need.

\section{THE IMPORTANCE OF VARIABILITY}

Genetic mouse models enable us to study phenotype in a highly controlled system under well controlled conditions. They can help to tease out how individual variation arises and how it impacts disease, but only if rigorous statistical and unbiased blinded approaches to analysis are taken $(80,81)$. This variation may highlight key cellular pathways, as exemplified in human GWAS, and it provides a potential basis for dissecting individual responses to disease processes and therapeutics. However, as with humans, we still understand comparatively little of what causes variation in individual mice.

Age, gender and genetic background are well-known and significant sources of variation in mouse studies. For example, a single well-defined mutation can result in markedly different phenotypes when bred onto different inbred mouse lines, which have homogeneous (within the inbred line) but different (between inbred lines) genetic backgrounds $(60,82)$. This includes 'collaborative cross' mice, and 'recombinant inbred' mice, designed to have known variation in their genetic background to help map the genetic components of complex gene-environment interactions $(83,84)$. Not surprisingly, therefore, those breeding mouse lines go to great lengths to try and maintain a standard background and avoid genetic drift over time (85). In working with different substrains of individual inbred lines, we may have expectations that sub-strains used in different laboratories will be similar to each other, whereas in fact they can be markedly different. For example, the widely used C57BL/6J and C57BL/6N sub-strains have some notable phenotypic differences such as reduced motor performance in the $\mathrm{C} 57 \mathrm{BL} / 6 \mathrm{~N}$ compared to the $\mathrm{C} 57 \mathrm{BL} / 6 \mathrm{~J}$ sub-strain (86).

Genetic background effects can in fact give great biological insight as this common source of variation can be used to help identify modifier loci (87). For example, a modifier locus for human Dravet's syndrome (a severe, infant-onset epileptic encephalopathy) was identified using the straindependent epilepsy phenotype of a mouse carrying a $\operatorname{Scn} 1 a$ (sodium voltage-gated channel $\alpha$ subunit 1) mutation (88). Another example comes from studies of the Cacna1c gene encoding calcium voltagegated channel subunit $\alpha 1 \mathrm{C}$ and the $T c f 7 / 2$ gene encoding transcription factor 7 like 2, which have been implicated in human psychiatric disorders and in type 2 diabetes, respectively. Crosses of null mutations in these genes onto 30 different inbred lines showed that opposite effects from the same allele could occur depending on the genetic background, and that sex could also have a marked effect on phenotype (89). Thus, if we confine ourselves to studying one inbred line, or one sex, we may miss 
the panoply of variation arising from a single mutation. Rather surprisingly, the genetic background in a mouse cross can also include 'inert' control elements such as the tetracycline transactivator, which in theory only exert an effect when activated, but in practice may independently affect phenotype (90).

Other sources of variation such as parent-of-origin effects (when phenotype from an allele depends on which parent contributed the allele)(91) (which may warrant phenotyping wildtype offspring of mutant mice) and contributions from transgenerational inheritance $(92,93)$ may be important sources of variation for some phenotypes. Similarly, even when closely defined hybrid lines are used in highly controlled environments, litter-of-origin effects (i.e. the phenotype depends on which litter a mouse comes from) may arise. Thus, mice from the same litters should be distributed across experimental cages, as demonstrated in a carefully controlled therapeutic preclinical trial in mice modeling certain aspects of HD; this study noted sources of variability such as maternal nutritional status which may result in pups from the same litter having similar characteristics, regardless of genotype, and in fact the authors saw a modest effect of litter of origin on a behavioural phenotype of their mice (94).

It is important to identify and understand the many other sources of phenotypic variation so that we can fully characterize our animals, and thus better understand the variation in human health and disease (95). This may be crucial for understanding gene interactions and also gene-environment interactions, both of which can exert huge influences on disease etiology and progression. Here, we briefly discuss some of the conditions leading to phenotypic variability between studies.

\section{Life history, well-being and stress}

Life history is an important determinant of disease, for a mouse and for a human. For example, the level of adversity during development biases protective stress or anxiety responses in order to better adapt an organism to the environment into which it was born (resilience), but then these same responses persist into adulthood (96-98). Notably, this may not always be helpful later in life if there is a mismatch between the developmental and adult environments. Mice, like humans, are affected by early life trauma, which can alter brain structure, produce epigenetic and genomic effects and lead to neuropsychiatric phenotypes later in life (99-104). Stress can also influence the in utero environment such as when effects of maternal inflammatory responses lead to brain and behaviour abnormalities in offspring (105) or when prenatal stress disrupts the maternal vaginal microbiome leading to lasting effects on the gut and hypothalamus of male offspring (106) .

Indeed, stress is a hugely important determinant of pathology and behavioral sequelae in neurodegenerative disorders. Stress and the hypothalamic-pituitary-adrenal (HPA) axis are key 
determinants of the concentrations of circulating corticosteroid hormones, which can have powerful effects on neurodegenerative phenotypes. For example, stress, either from chronic isolation or as the result of an acute challenge, can lead to increased $A \beta$ peptide in brain interstitial fluid in a transgenic mouse model of $A \beta$ deposition used to study $A D(101)$.

Social interactions play a role in mouse and human well-being, and can markedly affect phenotypes. Single housing of social animals such as mice causes stress and aberrant behaviors (107). Furthermore, social hierarchies and dominant/submissive relationships may have a profound impact on mouse well-being and so, for example, the population density of a cage may affect the phenotype (108). Likewise, human relationships are important for outcomes in neurodegeneration. For example, in an ALS patient cohort, being married was associated with an 8-month median longer survival time compared to single individuals (109). Interestingly, it now appears that the genetic status of those surrounding an individual may also be important for its well-being. Notably, in mice, several traits --from wound healing to anxiety ---are affected by the genotype of cage mates (110).

Ambient temperature is a source of variability we rarely consider because mice are generally housed at temperatures of between $20-26^{\circ} \mathrm{C}$. However, this may be too cold, as mice have activated thermogenesis at these temperatures to maintain their normal body temperature. This mild chronic cold stress affects tumor formation and metastasis, potentially confounding our understanding of these processes. This may also be true for neurodegenerative mechanisms (111) and for metabolic pathways (112). Notably, some researchers, including those engaged in therapeutics studies, are moving to keep their mice, inbred strains or outbred strains, in environments that as closely as possible mimic those of wild mice (113).

\section{Circadian rhythms and sleep}

Circadian rhythms can affect experimental and pathological outcomes in neurodegeneration research (114). In fact, the authors collect tissue samples only at specific times of the day to avoid variations in gene expression arising from circadian rhythms; for example, normal daily cycles in body temperature affect alternative splicing of transcripts (115). Similarly, behavioral testing is usually carried out at the same time of day within an experiment in order to minimize variability. However, as a consequence, we may miss phenotypic variation across the 24 -hour cycle. This may be particularly important as disruption of normal circadian rhythms can impact biochemical pathways underlying neuropathology and the expression of their behavioral sequelae (116). Moreover, it is notable that many laboratories conduct behavioural tests during the animals' subjective day, despite the fact that the species is nocturnal. 
Related to circadian effects, is the importance of sleep and sleep disturbance in the development of neurodegenerative phenotypes. For example, sleep plays a critical role in the clearance of $A \beta$ from the brain (117). Thus, sleep deprivation and sleep disruption may impact $A \beta$ deposition and exacerbate disease phenotypes and progression by affecting $A \beta$ removal from the brain (118). Moreover, sleep disruption per se may also directly exacerbate cognitive impairments arising from neuropathological changes, similar to its putative effects in neuropsychiatric conditions (119).

\section{Exercise and environmental enrichment}

Physical exercise plays an important role in modulating brain function. Exercise results in the release of trophic factors including brain-derived neurotrophic factor (BDNF) (120), and promotes neurogenesis in the dentate gyrus of the hippocampus (121-123), a brain area implicated in neurodegeneration and its behavioral sequelae. Exercise, such as voluntary wheel running in mice, enhances both glymphatic influxand improves cognitive performance on behavioural tasks $(123,124)$. Environmental enrichment can also have an enormous impact on the development of behavioral and histopathologial trajectories in mouse models of neurodegenerative disease. For example, the onset of cerebral volume reduction and motor disorders are delayed in an HD mouse model if the animals are exposed to a stimulating environment from four weeks of age $(125,126)$. This may parallel the concept of cognitive reserve, such that people who frequently perform cognitively demanding tasks may be less likely to suffer from deterioration of brain function (127).

\section{Diet, the microbiome and inflammation}

An advantage of working with mice is to be able to study the effects of diet on any given phenotype (128). However, often scientists may not even be aware of any variation in mouse diet. Many mouse chows contain soy and so may result in a relatively large intake of phytoestrogens, potentially influencing disease outcomes such as anxiety or pain. Exposure to phytoestrogens in utero also has effects on disease outcomes in adulthood. However, the amount of soy and therefore phytoestrogens can vary between batches of chow, thus potentially adding to variability in phenotypes (129). This may be relevant to modeling disorders such as ALS in which estrogen may have a protective effect (130).

Alterations in the gut microbiome, whether derived from diet or otherwise, can also have a great influence on biochemical, neural and behavioral phenotypes $(131,132)$, and lab mice have a gut microbiome that is notably different from their wild relatives (133). Strikingly, transplant of gut bacteria from PD patients into transgenic mice overexpressing $\alpha$-synuclein exacerbated motor deficits, microglia activation and pathology, an effect which, in turn, could be ameliorated by antibiotic 
treatment (134). Recently, a species of Lactobacillus has been found to reverse the social deficits, akin to human autism spectrum disorder, found in progeny of mothers fed with high-fat diet; intriguingly, these effects act via the vagus nerve, and not by restoring the composition of the offsprings' gut microbiome (135). Efforts are now underway to define the effects of the wild mouse gut microbiota in promoting host fitness (133).

The overall health status of the mouse colony can greatly affect the cellular components of the innate and adaptive immune systems, which may affect phenotypes in mouse models (136). CNS inflammation has long been established as important in the progression of neurodegenerative disorders (137). Recently, it has been found that systemic inflammation also plays a key role (138). The adaptive pathways by which signals of systemic inflammation are communicated to the brain have now been well described, and it is becoming increasingly clear that excessive or prolonged activation of these pathways is detrimental to the brain (105), and can exacerbate neurodegenerative conditions. Thus, health status may be an important determinant of the rate of progression of pathology in a given mouse model of neurodegenerative conditions. Indeed, this may relate to a much bigger story about how the health status of human subjects impacts disease etiology and progression. In particular, infection and inflammation may be key drivers of disease processes, including those underlying neurodegenerative disease $(73,139)$.

\section{Making sense of behavior}

A further major source of variation across laboratories and across studies comes from the behavioral phenotyping of mice. Often the use of different behavioral tasks and different tests protocols in different laboratories means that researchers are not actually assessing the same behavioral processes in their mouse studies, and hence different results can be obtained. Even small differences in experimental protocol (such as the amount or nature of any pretraining, duration or nature of stimuli, inter-trial interval, motivational state) can have a major influence on the way rodents might solve a particular task and hence the sensitivity of the animals to a given experimental manipulation. This reflects the multiple memory mechanisms and cognitive processes underlying complex behaviors in both rodents and humans. Again, understanding the sources of this variability across studies, in terms of behavioural outcomes, may shed light on disease processes.

A key related question when using genetically modified mouse models of neurodegenerative disorders is whether the behavior we are studying in our rodents is accurately modeling the appropriate behavior in humans? Therefore, it is essential to identify the psychological process that is disrupted in a given mouse model, to determine whether this is the same psychological process that underlies impairment in human patients. A clear understanding of these psychological processes will 
also greatly aid in identifying the underlying neural circuits and mechanisms that are affected in the animal model. Importantly, this requires the characterization of the mouse model across several behavioral tests, which allows the precise nature of the impairment to be inferred by comparing what the mouse can and cannot do. It is not possible to determine the key psychological process that is disrupted in a disease model from studying mice in just a single task.

In a number of situations, classical rodent assays of cognitive behavior may not always model the human cognitive process as intended (Figure 3). For example, do deficits in Morris watermaze performance in mouse models of neurodegeneration always indicate memory impairment (140)? Is working memory as studied in rodents undertaking a win-shift maze task (for example, the radial maze or T-maze task) really the equivalent of working memory in humans as studied, for example, in the $\mathrm{N}$ back task or the digit span task (141)? Instead of using working memory, rodents may often solve these tasks using familiarity judgements based on short-term habituation processes (141). Is contextual fear conditioning in mice measuring episodic memory or conditioned anxiety (a change in emotional state).? There are also a number of potential problems with this test, including generic issues with interpreting freezing data in animals that exhibit marked locomotor hyperactivity, including many mouse models of neurodegenerative disease. Examples from basic science experiments have highlighted these issues but the questions raised from these studies also likely apply to tests with neurodegenerative mouse models. This demonstrates the importance of extending behavioral tests to provide a more comprehensive and precise description of any cognitive and psychological deficits in the animal model.

In the Morris watermaze swim test, for example, it is imperative to include the appropriate control tasks that are well matched in terms of sensorimotor and motivational task demands (visual acuity, emotionality, stress, swim time, difficulty, etc.). In addition, a battery of spatial memory tests also needs to be included to allow the generality of any findings from the watermaze swim test to be ascertained under different behavioral conditions that are unaffected by performance factors like thigmotaxis (continually swimming close to the side wall of the pool) and floating behavior. Both of these behaviors present confounds in watermaze studies conducted in mouse models of neurodegeneration (140). The distance that the platform is located from the side wall of the pool may thus be an important experimental variable in such studies (142). If a watermaze deficit in a mouse model of neurodegeneration is due to thigmotaxis (possibly as the result of altered anxiety), any drug treatment developed from such an assay may be unlikely to remedy cognitive symptoms in patients. Conversely, however, increased thigmotaxis or enhanced floating behavior likely reflects important behavioral responses to a given aversive situation. Understanding these behaviors and the contribution that a particular genetic change or its neuropathological sequelae make to these 
phenotypes, may provide important information about emotionality phenotypes (such as depression, anxiety) that can occur in neurodegenerative conditions in human patients.

\section{Phenotyping is a group activity}

Importantly, the best way of working with mice, which also likely involves using the fewest animals, is to work collaboratively with scientists with expertise in different areas---from genetics to physiology/endocrinology, from transcriptomics to developmental/behavioral biology, from protein chemistry and neuroimaging to immunology---in concert with clinical experts for each neurodegenerative disease. Multidisciplinary teams enable us to maximise what we learn from each model including pleiotropic effects (separating these from co-morbidities, for example), and help us to avoid maintaining too narrow a focus, for example, on just one specific cell type. Each mouse mutant should undergo broad phenotyping of the sort provided by the International Mouse Phenotyping Consortium (81), as well as in-depth investigations into disease mechanisms by disease specialists.

Metabolomic studies provide a good example of why studying neurodegeneration should not only be the work of neuroscientists. One of the most distressing aspects of ALS and HD is weight loss and this may correlate with poor clinical outcome. Furthermore, low body mass index is thought to be a risk factor for ALS (143). In ALS, we know there are lipid disturbances in both humans and mouse models but why these arise remains unknown. This could turn out to be an important avenue of research for those developing disease-modifying treatments.

\section{TRANSLATION: THE ELUSIVE FRONTIER}

Despite the hundreds of mouse models of human neurodegenerative disease, we still have no cure for any major form of neurodegeneration and only extremely limited treatments for just a handful of these diseases. Many insightful articles have been written about moving forward from mouse studies of disease mechanism and the difficulties of translating therapies that modulate disease in mice to successful human clinical trials [for example, see $(27,125-128)]$. Here, we suggest that variability in both mouse and human may be an important factor underlying current translation failures, but also may be a source of insight into disease mechanisms.

\section{What is translation?}

The translation phrase "from bench to bedside" encompasses two separate processes: (1) the discovery of mechanisms of disease pathogenesis, and (2) the development of new therapies and their testing in clinical trials. In our view, mouse models have great utility for dissecting biological processes, but so far have not proven particularly useful or practical for producing treatments that work in 
humans, with a few notable exceptions including the success of antisense oligonucleotide therapies for treating SMA) (148). Currently, therefore, the major and proven utility of mouse models lies in identifying disease mechanisms. Their potential utility (or lack thereof) as drug screening tools may only become apparent once we have a better understanding of both pathomechanisms and the reasons why current attempts at translation have so often failed. We argue that the answer to the latter question may partly lie within our appreciation of the variability in our mouse studies and also the great variability within the human clinical population.

\section{From mouse and mechanism to medicine}

In biomedical studies, we generally only look at a snapshot of disease. For technical or financial reasons, we study genetic mutations in one or two inbred mouse lines only, or worse yet, on ill-defined outbred mouse lines that are usually a lot more inbred than expected (149) [although outbred lines certainly have their uses (150), and abuses (151)]. We tend to study single gene mutations even though most human disease is a mix of genes plus environment, and even rare monogenic diseases may show synergistic effects between unrelated genetic loci (152).

As scientists, our cultural viewpoint is to minimise variation within our studies in order to maximise our chances of identifying significant differences between experimental and control conditions. To this end, we generate genetically modified mice on homogeneous genetic backgrounds and maintain these animals under constant environmental conditions. It follows that any important discoveries arising from these animal studies, particularly with respect to therapeutics that modulate biochemical pathways and networks, may only be relevant to a limited subgroup of the clinical population.

It is not surprising, therefore, that when attempts are made to translate findings in animal models to the much more heterogeneous human clinical population (which varies in terms of age, gender, genetic background, environment, and life history), these attempts have failed consistently. Put another way, the homogeneity of approach that benefits reproducibility and increases statistical power in preclinical studies (and yet that is still remarkably difficult to carry out in mice) may come at the cost of reducing generalizabilty when it comes to translation of therapeutics from mouse to human (145). This issue is not exclusive to animal models of neurodegeneration, but instead reflects a general problem in making the crucial step between preclinical studies in animals and clinical trials for many human disorders, as has been highlighted in the stroke field $(145,153)$ as well as in neurodegeneration studies (154). Researchers have made suggestions for improving this process, such as performing mouse studies across several independent laboratories in order to mimic multi-center clinical trials in humans. Nevertheless, at the heart of this 
issue remain both the inherent variability of pre-clinical mouse studies and, possibly even more important, the pronounced variability of human clinical patient populations. Crucially, therefore, embracing rather than rejecting variability in our mouse studies, and then understanding both its sources and its underlying mechanisms, could be of great benefit for successful translation to clinical patient sub-groups. Moreover, it seems likely that questions regarding the utility (or otherwise) of mouse models for determining pathomechanisms relevant to human neurodegenerative conditions, and ultimately as drug screening tools, can only be properly answered once we have addressed this central issue of variability.

Although currently we have few treatments for human neurodegeneration, and a relatively limited understanding of the mechanisms underlying neuronal death, we are also racing into a new era of personalised medicine. By working with the appropriate mouse models to address specific questions and by examining causes of variation in these models, we can help to identify diverse mechanisms of neuronal dysfunction and neuronal death. Variation may be particularly important for neurodegenerative disorders given the heterogeneous nature of many of these conditions, and given the current drive to identify biomarkers allowing stratification of patient subgroups, precision medicine, early diagnosis and response to therapeutic intervention.

It is impossible to standardize all experimental conditions across laboratories, but instead we need to recognise variation and use it as a source of insight. Variation has hitherto been seen as a problem and something that should be diminished and reduced at all costs. Here, we suggest that variation could be an opportunity that may allow us to understand and identify disease mechanisms and risk factors, and at the same time elucidate treatment strategies, on an individual by individual basis. Indeed, embracing and understanding variation may be of great benefit for translation. Of course, identifying the sources of variation will not be straightforward but, nevertheless, we suggest the following agenda for working with mouse models of neurodegeneration.

We believe mouse models should be studied in response to a specific need, for example, animals with slow disease progression and relatively mild phenotypes would be best used for understanding early disease pathogenesis, but these animals may not be useful for clinical trials of therapeutics developed for treating late stage human disease (Figure 2). Both scientists and funding agencies should take a more sophisticated approach to each mouse model and not expect complete recapitulation of the human disease. Mouse models often may be better suited as tools for understanding the role of a specific gene or protein, or a specific aspect of the disease process, rather than as primary drug-screening tools.

To capture how variation arises, we need considerably more detail than is often provided in research papers (95). In an attempt to ensure mouse phenotypes are fully defined in the literature, 
the UK National Centre for the Replacement, Refinement and Reduction of Animals in Research (NC3Rs) introduced a checklist of information required for any paper describing animal research called the 'ARRIVE guidelines' (Animal Research: Reporting of In Vivo Experiments) (146). Undertaking animal studies in accordance with the ARRIVE guidelines should mean some sources of variability are clearly reported (146), and so we can begin to understand their effects on mouse phenotypes. Furthermore, peer review should be rigorous to ensure accurate reporting of such crucial experimental details. However, more than anything, as a scientific community we need to change our attitude to the variability in our data. We need to create long-term metadata repositories in which data are deposited and made available to the wider community for critical analysis and further phenotypic screening.

New approaches to working with mice are on their way. For example, Home Cage analysis enables us to capture aspects of behavior not seen when humans are around (155). New informatics approaches including machine learning could help us to find new phenotypes from the immense amount of data generated by Home Cage analysis. Developing ontologies for human-mouse phenotypes, in combination with new imaging and computational methods to help cross-reference between mouse and human data sets, will greatly enrich our understanding of human (and mouse) biology and will help to elucidate neurodegenerative processes, but only if we also take variation into account.

\section{Acknowledgements}

We thank the reviewers and Giampietro Schiavo for insightful comments, and our many colleagues worldwide who work in different capacities with mouse models to understand and treat human neurodegenerative disease. EMCF undertakes no paid or unpaid consulting; DMB undertakes no paid consulting and is a member of Ely Lily's Centre for Cognitive Neuroscience (unpaid). 


\section{REFERENCES}

1. Alzheimer's DiseaseInternational, The state of the art of dementia research: new frontiers. (2018).

2. Parkinson's Disease Foundation, Statistics on Parkinson's. (2016).

3. A. Conte, S. Lattante, M. Zollino, G. Marangi, M. Luigetti, A. Del Grande, S. Servidei, F. Trombetta, M. Sabatelli, P525L FUS mutation is consistently associated with a severe form of juvenile amyotrophic lateral sclerosis. Neuromuscular disorders : NMD 22, 73-75 (2012).

4. R. H. Waterston, K. Lindblad-Toh, E. Birney, J. Rogers, J. F. Abril, P. Agarwal, R. Agarwala, R. Ainscough, M. Alexandersson, P. An, S. E. Antonarakis, J. Attwood, R. Baertsch, J. Bailey, K. Barlow, S. Beck, E. Berry, B. Birren, T. Bloom, P. Bork, M. Botcherby, N. Bray, M. R. Brent, D. G. Brown, S. D. Brown, C. Bult, J. Burton, J. Butler, R. D. Campbell, P. Carninci, S. Cawley, F. Chiaromonte, A. T. Chinwalla, D. M. Church, M. Clamp, C. Clee, F. S. Collins, L. L. Cook, R. R. Copley, A. Coulson, O. Couronne, J. Cuff, V. Curwen, T. Cutts, M. Daly, R. David, J. Davies, K. D. Delehaunty, J. Deri, E. T. Dermitzakis, C. Dewey, N. J. Dickens, M. Diekhans, S. Dodge, I. Dubchak, D. M. Dunn, S. R. Eddy, L. Elnitski, R. D. Emes, P. Eswara, E. Eyras, A. Felsenfeld, G. A. Fewell, P. Flicek, K. Foley, W. N. Frankel, L. A. Fulton, R. S. Fulton, T. S. Furey, D. Gage, R. A. Gibbs, G. Glusman, S. Gnerre, N. Goldman, L. Goodstadt, D. Grafham, T. A. Graves, E. D. Green, S. Gregory, R. Guigo, M. Guyer, R. C. Hardison, D. Haussler, Y. Hayashizaki, L. W. Hillier, A. Hinrichs, W. Hlavina, T. Holzer, F. Hsu, A. Hua, T. Hubbard, A. Hunt, I. Jackson, D. B. Jaffe, L. S. Johnson, M. Jones, T. A. Jones, A. Joy, M. Kamal, E. K. Karlsson, D. Karolchik, A. Kasprzyk, J. Kawai, E. Keibler, C. Kells, W. J. Kent, A. Kirby, D. L. Kolbe, I. Korf, R. S. Kucherlapati, E. J. Kulbokas, D. Kulp, T. Landers, J. P. Leger, S. Leonard, I. Letunic, R. Levine, J. Li, M. Li, C. Lloyd, S. Lucas, B. Ma, D. R. Maglott, E. R. Mardis, L. Matthews, E. Mauceli, J. H. Mayer, M. McCarthy, W. R. McCombie, S. McLaren, K. Mclay, J. D. McPherson, J. Meldrim, B. Meredith, J. P. Mesirov, W. Miller, T. L. Miner, E. Mongin, K. T. Montgomery, M. Morgan, R. Mott, J. C. Mullikin, D. M. Muzny, W. E. Nash, J. O. Nelson, M. N. Nhan, R. Nicol, Z. Ning, C. Nusbaum, M. J. O'Connor, Y. Okazaki, K. Oliver, E. O. Larty, L. Pachter, G. Parra, K. H. Pepin, J. Peterson, P. Pevzner, R. Plumb, C. S. Pohl, A. Poliakov, T. C. Ponce, C. P. Ponting, S. Potter, M. Quail, A. Reymond, B. A. Roe, K. M. Roskin, E. M. Rubin, A. G. Rust, R. Santos, V. Sapojnikov, B. Schultz, J. Schultz, M. S. Schwartz, S. Schwartz, C. Scott, S. Seaman, S. Searle, T. Sharpe, A. Sheridan, R. Shownkeen, S. Sims, J. B. Singer, G. Slater, A. Smit, D. R. Smith, B. Spencer, A. Stabenau, N. S. StrangeThomann, C. Sugnet, M. Suyama, G. Tesler, J. Thompson, D. Torrents, E. Trevaskis, J. Tromp, C. Ucla, A. U. Vidal, J. P. Vinson, A. C. von Niederhausern, C. M. Wade, M. Wall, R. J. Weber, R. B. Weiss, M. C. Wendl, A. P. West, K. Wetterstrand, R. Wheeler, S. Whelan, J. Wierzbowski, D. Willey, S. Williams, R. K. Wilson, E. Winter, K. C. Worley, D. Wyman, S. Yang, S. P. Yang, E. M. Zdobnov, M. C. Zody, E. S. Lander, Initial sequencing and comparative analysis of the mouse genome. Nature 420, 520-562 (2002).

5. F. K. Wiseman, T. Al Janabi, J. Hardy, A. Karmiloff-Smith, D. Nizetic, V. L. J. Tybulewicz, E. M. C. Fisher, A. Strydom, A genetic cause of Alzheimer disease: mechanistic insights from Down syndrome. Nature Reviews Neuroscience 16, 564-574 (2015).

6. Y. Herault, J. M. Delabar, E. M. C. Fisher, V. L. J. Tybulewicz, E. Yu, V. Brault, Rodent models in Down syndrome research: impact and future opportunities. Dis Model Mech 10, 1165-1186 (2017).

7. A. O'Doherty, S. Ruf, C. Mulligan, V. Hildreth, M. L. Errington, S. Cooke, A. Sesay, S. Modino, L. Vanes, D. Hernandez, J. M. Linehan, P. T. Sharpe, S. Brandner, T. V. P. Bliss, D. J. Henderson, D. Nizetic, V. L. J. Tybulewicz, E. M. C. Fisher, An aneuploid mouse strain carrying human chromosome 21 with Down syndrome phenotypes. Science (New York, N.Y.) 309, 2033-2037 (2005). 
8. T. Yu, Z. Y. Li, Z. P. Jia, S. J. Clapcote, C. H. Liu, S. M. Li, S. Asrar, A. Pao, R. Q. Chen, N. Fan, S. Carattini-Rivera, A. R. Bechard, S. S. Spring, R. M. Henkelman, G. Stoica, S. I. Matsui, N. J. Nowak, J. C. Roder, C. Chen, A. Bradley, Y. E. Yu, A mouse model of Down syndrome trisomic for all human chromosome 21 syntenic regions. Human molecular genetics 19, 2780-2791 (2010).

9. X. Sturgeon, K. J. Gardiner, Transcript catalogs of human chromosome 21 and orthologous chimpanzee and mouse regions. Mammalian Genome 22, 261-271 (2011).

10. E. D. Hamlett, H. A. Boger, A. Ledreux, C. M. Kelley, E. J. Mufson, M. F. Falangola, D. N. Guilfoyle, R. A. Nixon, D. Patterson, N. Duval, A. C. Granholm, Cognitive impairment, neuroimaging, and Alzheimer neuropathology in mouse models of Down syndrome. Curr Alzheimer Res 13, 35-52 (2016).

11. T. W. Bebee, C. E. Dominguez, D. S. Chandler, Mouse models of SMA: tools for disease characterization and therapeutic development. Human Genetics 131, 1277-1293 (2012).

12. E. V. Fletcher, C. M. Simon, J. G. Pagiazitis, J. I. Chalif, A. Vukojicic, E. Drobac, X. Wang, G. Z. Mentis, Reduced sensory synaptic excitation impairs motor neuron function via Kv2.1 in spinal muscular atrophy. Nature neuroscience 20, 905-916 (2017).

13. C. Sheridan, Gene therapy rescues newborns with spinal muscular atrophy. Nature biotechnology 36, 669-670 (2018).

14. A. Breschi, T. R. Gingeras, R. Guigo, Comparative transcriptomics in human and mouse. Nature reviews. Genetics 18, 425-440 (2017).

15. S. Lin, Y. Lin, J. R. Nery, M. A. Urich, A. Breschi, C. A. Davis, A. Dobin, C. Zaleski, M. A. Beer, W. C. Chapman, T. R. Gingeras, J. R. Ecker, M. P. Snyder, Comparison of the transcriptional landscapes between human and mouse tissues. Proceedings of the National Academy of Sciences of the United States of America 111, 17224-17229 (2014).

16. J. Vierstra, E. Rynes, R. Sandstrom, M. Zhang, T. Canfield, R. S. Hansen, S. Stehling-Sun, P. J. Sabo, R. Byron, R. Humbert, R. E. Thurman, A. K. Johnson, S. Vong, K. Lee, D. Bates, F. Neri, M. Diegel, E. Giste, E. Haugen, D. Dunn, M. S. Wilken, S. Josefowicz, R. Samstein, K. H. Chang, E. E. Eichler, M. De Bruijn, T. A. Reh, A. Skoultchi, A. Rudensky, S. H. Orkin, T. Papayannopoulou, P. M. Treuting, L. Selleri, R. Kaul, M. Groudine, M. A. Bender, J. A. Stamatoyannopoulos, Mouse regulatory DNA landscapes reveal global principles of cis-regulatory evolution. Science (New York, N.Y.) 346, 1007-1012 (2014).

17. F. Yue, Y. Cheng, A. Breschi, J. Vierstra, W. S. Wu, T. Ryba, R. Sandstrom, Z. H. Ma, C. Davis, B. D. Pope, Y. Shen, D. D. Pervouchine, S. Djebali, R. E. Thurman, R. Kaul, E. Rynes, A. Kirilusha, G. K. Marinov, B. A. Williams, D. Trout, H. Amrhein, K. Fisher-Aylor, I. Antoshechkin, G. DeSalvo, L. H. See, M. Fastuca, J. Drenkow, C. Zaleski, A. Dobin, P. Prieto, J. Lagarde, G. Bussotti, A. Tanzer, O. Denas, K. W. Li, M. A. Bender, M. H. Zhang, R. Byron, M. T. Groudine, D. McCleary, L. Pham, Z. Ye, S. Kuan, L. Edsall, Y. C. Wu, M. D. Rasmussen, M. S. Bansal, M. Kellis, C. A. Keller, C. S. Morrissey, T. Mishra, D. Jain, N. Dogan, R. S. Harris, P. Cayting, T. Kawli, A. P. Boyle, G. Euskirchen, A. Kundaje, S. Lin, Y. Lin, C. Jansen, V. S. Malladi, M. S. Cline, D. T. Erickson, V. M. Kirkup, K. Learned, C. A. Sloan, K. R. Rosenbloom, B. L. De Sousa, K. Beal, M. Pignatelli, P. Flicek, J. Lian, T. Kahveci, D. Lee, W. J. Kent, M. R. Santos, J. Herrero, C. Notredame, A. Johnson, S. Vong, K. Lee, D. Bates, F. Neri, M. Diegel, T. Canfield, P. J. Sabo, M. S. Wilken, T. A. Reh, E. Giste, A. Shafer, T. Kutyavin, E. Haugen, D. Dunn, A. P. Reynolds, S. Neph, R. Humbert, R. S. Hansen, M. De Bruijn, L. Selleri, A. Rudensky, S. Josefowicz, R. Samstein, E. E. Eichler, S. H. Orkin, D. Levasseur, T. Papayannopoulou, K. H. Chang, A. Skoultchi, S. Gosh, C. Disteche, P. Treuting, Y. Wang, M. J. Weiss, G. A. Blobel, X. Cao, S. Zhong, T. Wang, P. J. Good, R. F. Lowdon, L. B. Adams, X. Q. Zhou, M. J. Pazin, E. A. Feingold, B. Wold, J. Taylor, A. Mortazavi, S. M. Weissman, J. A. Stamatoyannopoulos, M. P. Snyder, R. Guigo, T. R. Gingeras, D. M. Gilbert, R. C. Hardison, M. A. Beer, B. Ren, A comparative encyclopedia of DNA elements in the mouse genome. Nature 515, 355-364 (2014). 
18. Y. Lee, D. C. Rio, Mechanisms and Regulation of Alternative Pre-mRNA Splicing. Annual Review of Biochemistry, Vol 84 84, 291-323 (2015).

19. F. B. Gao, S. Almeida, R. Lopez-Gonzalez, Dysregulated molecular pathways in amyotrophic lateral sclerosis-frontotemporal dementia spectrum disorder. EMBO J 36, (2017).

20. K. M. Schoch, S. L. DeVos, R. L. Miller, S. J. Chun, M. Norrbom, D. F. Wozniak, H. N. Dawson, C. F. Bennett, F. Rigo, T. M. Miller, Increased 4R-Tau induces pathological changes in a humantau mouse model. Neuron 90, 941-947 (2016).

21. B. Ataman, G. L. Boulting, D. A. Harmin, M. G. Yang, M. Baker-Salisbury, E. L. Yap, A. N. Malik, K. Mei, A. A. Rubin, I. Spiegel, E. Durresi, N. Sharma, L. S. Hu, M. Pletikos, E. C. Griffith, J. N. Partlow, C. R. Stevens, M. Adli, M. Chahrour, N. Sestan, C. A. Walsh, V. K. Berezovskii, M. S. Livingstone, M. E. Greenberg, Evolution of Osteocrin as an activity-regulated factor in the primate brain. Nature 539, 242-247 (2016).

22. I. W. Deveson, M. E. Brunck, J. Blackburn, E. Tseng, T. Hon, T. A. Clark, M. B. Clark, J. Crawford, M. E. Dinger, L. K. Nielsen, J. S. Mattick, T. R. Mercer, Universal Alternative Splicing of Noncoding Exons. Cell Syst 6, 245-255 e245 (2018).

23. C. D. Bragg, Disease onset in X-linked dystonia-parkinsonism correlated with expansion of a hexameric repeat within an SVA retrotransposon in TAF1. PNAS PNAS 2017 December, 114 (51) E11020-E11028. https://doi.org/10.1073/pnas.1712526114 (2018).

24. M. Taniguchi-Ikeda, K. Kobayashi, M. Kanagawa, C. C. Yu, K. Mori, T. Oda, A. Kuga, H. Kurahashi, H. O. Akman, S. DiMauro, R. Kaji, T. Yokota, S. Takeda, T. Toda, Pathogenic exontrapping by SVA retrotransposon and rescue in Fukuyama muscular dystrophy. Nature 478, 127-131 (2011).

25. M. Kapur, C. E. Monaghan, S. L. Ackerman, Regulation of mRNA Translation in Neurons-A Matter of Life and Death. Neuron 96, 616-637 (2017).

26. Z. Melamed, J. Lopez-Erauskin, M. W. Baughn, O. Zhang, K. Drenner, Y. Sun, F. Freyermuth, M. A. McMahon, M. S. Beccari, J. W. Artates, T. Ohkubo, M. Rodriguez, N. Lin, D. Wu, C. F. Bennett, F. Rigo, S. Da Cruz, J. Ravits, C. Lagier-Tourenne, D. W. Cleveland, Premature polyadenylationmediated loss of stathmin-2 is a hallmark of TDP-43-dependent neurodegeneration. Nature neuroscience 22, 180-190 (2019).

27. Y. Z. Zhu, C. Tazearslan, Y. Suh, Challenges and progress in interpretation of non-coding genetic variants associated with human disease. Exp Biol Med 242, 1325-1334 (2017).

28. E. Salta, B. De Strooper, Noncoding RNAs in neurodegeneration. Nature reviews. Neuroscience 18, 627-640 (2017).

29. G. Xu, Y. Ran, S. E. Fromholt, C. Fu, A. T. Yachnis, T. E. Golde, D. R. Borchelt, Murine Ab overproduction produces diffuse and compact Alzheimer-type amyloid deposits. Acta neuropathologica communications 3, 72 (2015).

30. C. M. Karch, D. R. Borchelt, Aggregation modulating elements in mutant human superoxide dismutase 1. Archives of Biochemistry and Biophysics 503, 175-182 (2016).

31. P. I. Joyce, P. Mcgoldrick, R. A. Saccon, W. Weber, P. Fratta, S. J. West, N. Zhu, S. Carter, V. Phatak, M. Stewart, M. Simon, S. Kumar, I. Heise, V. Bros-Facer, J. Dick, S. Corrochano, M. J. Stanford, T. V. Luong, P. M. Nolan, T. Meyer, S. Brandner, D. L. H. Bennett, P. H. Ozdinler, L. Greensmith, E. M. C. Fisher, A. Acevedo-Arozena, A novel SOD1-ALS mutation separates central and peripheral effects of mutant SOD1 toxicity. Human molecular genetics 24, 18831897 (2015).

32. S. H. Elsea, R. E. Lucas, The mousetrap: what we can learn when the mouse model does not mimic the human disease. ILAR journal / National Research Council, Institute of Laboratory Animal Resources 43, 66-79 (2002).

33. R. L. Perlman, Mouse models of human disease: An evolutionary perspective. Evol Med Public Health 2016, 170-176 (2016).

34. A. J. Hulbert, The links between membrane composition, metabolic rate and lifespan. Comp Biochem Physiol A Mol Integr Physiol 150, 196-203 (2008). 
35. M. E. Dickinson, A. M. Flenniken, X. Ji, L. Teboul, M. D. Wong, J. K. White, T. F. Meehan, W. J. Weninger, H. Westerberg, H. Adissu, C. N. Baker, L. Bower, J. M. Brown, L. B. Caddle, F. Chiani, D. Clary, J. Cleak, M. J. Daly, J. M. Denegre, B. Doe, M. E. Dolan, S. M. Edie, H. Fuchs, V. GailusDurner, A. Galli, A. Gambadoro, J. Gallegos, S. Guo, N. R. Horner, C. W. Hsu, S. J. Johnson, S. Kalaga, L. C. Keith, L. Lanoue, T. N. Lawson, M. Lek, M. Mark, S. Marschall, J. Mason, M. L. McElwee, S. Newbigging, L. M. Nutter, K. A. Peterson, R. Ramirez-Solis, D. J. Rowland, E. Ryder, K. E. Samocha, J. R. Seavitt, M. Selloum, Z. Szoke-Kovacs, M. Tamura, A. G. Trainor, I. Tudose, S. Wakana, J. Warren, O. Wendling, D. B. West, L. Wong, A. Yoshiki, C. International Mouse Phenotyping, L. Jackson, I. C. d. I. S. Infrastructure Nationale Phenomin, L. Charles River, M. R. C. Harwell, P. Toronto Centre for, I. Wellcome Trust Sanger, R. B. Center, D. G. MacArthur, G. P. Tocchini-Valentini, X. Gao, P. Flicek, A. Bradley, W. C. Skarnes, M. J. Justice, H. E. Parkinson, M. Moore, S. Wells, R. E. Braun, K. L. Svenson, M. H. de Angelis, Y. Herault, T. Mohun, A. M. Mallon, R. M. Henkelman, S. D. Brown, D. J. Adams, K. C. Lloyd, C. McKerlie, A. L. Beaudet, M. Bucan, S. A. Murray, High-throughput discovery of novel developmental phenotypes. Nature 537, 508-514 (2016).

36. R. A. Saccon, R. K. Bunton-Stasyshyn, E. M. Fisher, P. Fratta, Is SOD1 loss of function involved in amyotrophic lateral sclerosis? Brain 136, 2342-2358 (2013).

37. T. L. Nguyen, S. Vieira-Silva, A. Liston, J. Raes, How informative is the mouse for human gut microbiota research? Dis Model Mech 8, 1-16 (2015).

38. C. E. Hagan, B. Bolon, C. D. Keene, in Comparative anatomy and histology: a mouse and human atlas, P. M. Treuting, S. M. Dintzis, Eds. (Academic Press, 2012), chap. 20, pp. 339.

39. E. Boldog, T. E. Bakken, R. D. Hodge, M. Novotny, B. D. Aevermann, J. Baka, S. Borde, J. L. Close, F. Diez-Fuertes, S. L. Ding, N. Farago, A. K. Kocsis, B. Kovacs, Z. Maltzer, J. M. McCorrison, J. A. Miller, G. Molnar, G. Olah, A. Ozsvar, M. Rozsa, S. I. Shehata, K. A. Smith, S. M. Sunkin, D. N. Tran, P. Venepally, A. Wall, L. G. Puskas, P. Barzo, F. J. Steemers, N. J. Schork, R. H. Scheuermann, R. S. Lasken, E. S. Lein, G. Tamas, Transcriptomic and morphophysiological evidence for a specialized human cortical GABAergic cell type. Nature neuroscience 21, 11851195 (2018).

40. S. Dutta, P. Sengupta, Men and mice: Relating their ages. Life Sci 152, 244-248 (2016).

41. A. Carfi, M. Antocicco, V. Brandi, C. Cipriani, F. Fiore, D. Mascia, S. Settanni, D. L. Vetrano, R. Bernabei, G. Onder, Characteristics of adults with down syndrome: prevalence of age-related conditions. Frontiers in medicine 1, 51 (2014).

42. J. C. Stevens, G. T. Banks, M. F. Festing, E. M. Fisher, Quiet mutations in inbred strains of mice. Trends in molecular medicine 13, 512-519 (2007).

43. S. Lesage, A. Durr, M. Tazir, E. Lohmann, A. L. Leutenegger, S. Janin, P. Pollak, A. Brice, LRRK2 G2019S as a cause of Parkinson's disease in North African Arabs. New England Journal of Medicine 354, 422-423 (2006).

44. H. C. Fung, C. M. Chen, J. Hardy, D. Hernandez, A. Singleton, Y. R. Wu, Lack of G2019S LRRK2 mutation in a cohort of Taiwanese with sporadic Parkinson's disease. Movement Disorders 21, 880-881 (2006).

45. J. Chew, T. F. Gendron, M. Prudencio, H. Sasaguri, Y. J. Zhang, M. Castanedes-Casey, C. W. Lee, K. Jansen-West, A. Kurti, M. E. Murray, K. F. Bieniek, P. O. Bauer, E. C. Whitelaw, L. Rousseau, J. N. Stankowski, C. Stetler, L. M. Daughrity, E. A. Perkerson, P. Desaro, A. Johnston, K. Overstreet, D. Edbauer, R. Rademakers, K. B. Boylan, D. W. Dickson, J. D. Fryer, L. Petrucelli, Neurodegeneration. C9ORF72 repeat expansions in mice cause TDP-43 pathology, neuronal loss, and behavioral deficits. Science (New York, N.Y.) 348, 1151-1154 (2015).

46. C. Verbeeck, Q. Deng, M. Dejesus-Hernandez, G. Taylor, C. Ceballos-Diaz, J. Kocerha, T. Golde, P. Das, R. Rademakers, D. W. Dickson, T. Kukar, Expression of Fused in sarcoma mutations in mice recapitulates the neuropathology of FUS proteinopathies and provides insight into disease pathogenesis. Mol Neurodegener 7, 53 (2012). 
47. D. Young, Gene Therapy-Based Modeling of Neurodegenerative Disorders: Huntington's Disease. Methods Mol Biol 1382, 383-395 (2016).

48. I. Espuny-Camacho, A. M. Arranz, M. Fiers, A. Snellinx, K. Ando, S. Munck, J. Bonnefont, L. Lambot, N. Corthout, L. Omodho, E. Vanden Eynden, E. Radaelli, I. Tesseur, S. Wray, A. Ebneth, J. Hardy, K. Leroy, J. P. Brion, P. Vanderhaeghen, B. De Strooper, Hallmarks of Alzheimer's Disease in Stem-Cell-Derived Human Neurons Transplanted into Mouse Brain. Neuron 93, 1066-1081 e1068 (2017).

49. G. R. Mallucci, M. D. White, M. Farmer, A. Dickinson, H. Khatun, A. D. Powell, S. Brandner, J. G. Jefferys, J. Collinge, Targeting cellular prion protein reverses early cognitive deficits and neurophysiological dysfunction in prion-infected mice. Neuron 53, 325-335 (2007).

50. E. Szunyogova, H. Zhou, G. K. Maxwell, R. A. Powis, M. Francesco, T. H. Gillingwater, S. H. Parson, Survival Motor Neuron (SMN) protein is required for normal mouse liver development. Scientific reports 6, 34635 (2016).

51. L. O. S. Goodwin, E; Davis, T.D.; Urban, R.; He, H.; Braun, R.E.; Chesler, E.J.; Kumar, V.; van Min, M.; Ndukum, J.; Philip, V.M.; Reinholdt, L.G.; Svenson, K.; White, J.K.; Sasner, M.; Lutz, C.; Murray, S.A., Large-scale discovery of mouse transgenic integration sites revleals frequent structural variation and insertional mutagenesis. bioRxiv doi.org/10.1101/236307, (2017).

52. W. Robberecht, T. Philips, The changing scene of amyotrophic lateral sclerosis. Nature reviews. Neuroscience 14, 248-264 (2013).

53. D. Jaarsma, F. Rognoni, W. van Duijn, H. W. Verspaget, E. D. Haasdijk, J. C. Holstege, CuZn superoxide dismutase (SOD1) accumulates in vacuolated mitochondria in transgenic mice expressing amyotrophic lateral sclerosis-linked SOD1 mutations. Acta Neuropathol 102, 293305 (2001).

54. J. Collinge, M. S. Palmer, K. C. Sidle, A. F. Hill, I. Gowland, J. Meads, E. Asante, R. Bradley, L. J. Doey, P. L. Lantos, Unaltered susceptibility to BSE in transgenic mice expressing human prion protein. Nature 378, 779-783 (1995).

55. J. Scekic-Zahirovic, H. E. Oussini, S. Mersmann, K. Drenner, M. Wagner, Y. Sun, K. Allmeroth, S. Dieterle, J. Sinniger, S. Dirrig-Grosch, F. Rene, D. Dormann, C. Haass, A. C. Ludolph, C. LagierTourenne, E. Storkebaum, L. Dupuis, Motor neuron intrinsic and extrinsic mechanisms contribute to the pathogenesis of FUS-associated amyotrophic lateral sclerosis. Acta Neuropathol 133, 887-906 (2017).

56. F. Larroquette, L. Seto, P. L. Gaub, B. Kamal, D. Wallis, R. Lariviere, J. Vallee, R. Robitaille, H. Tsuda, Vapb/Amyotrophic lateral sclerosis 8 knock-in mice display slowly progressive motor behavior defects accompanying ER stress and autophagic response. Human molecular genetics 24, 6515-6529 (2015).

57. G. A. Smith, O. Isacson, S. B. Dunnett, The search for genetic mouse models of prodromal Parkinson's disease. Exp Neurol 237, 267-273 (2012).

58. A. Devoy, B. Kalmar, M. Stewart, H. Park, B. Burke, S. J. Noy, Y. Redhead, J. Humphrey, K. Lo, J. Jaeger, A. Mejia Maza, P. Sivakumar, C. Bertolin, G. Soraru, V. Plagnol, L. Greensmith, A. Acevedo Arozena, A. M. Isaacs, B. Davies, P. Fratta, E. M. C. Fisher, Humanized mutant FUS drives progressive motor neuron degeneration without aggregation in 'FUSDelta14' knockin mice. Brain 140, 2797-2805 (2017).

59. F. M. De Giorgio, C.; Fisher, E.M.C.; Acevdo-Arozena, A, Transgenic and physiological mouse models give insights into different aspects of amyotrophic lateral sclerosis. Dis Model Mech 12, dmm037424. doi:037410.031242/dmm.037424 (2019).

60. P. Fratta, P. Sivakumar, J. Humphrey, K. Lo, T. Ricketts, H. Oliveira, J. M. Brito-Armas, B. Kalmar, A. Ule, Y. Yu, N. Birsa, C. Bodo, T. Collins, A. E. Conicella, A. Mejia Maza, A. Marrero-Gagliardi, M. Stewart, J. Mianne, S. Corrochano, W. Emmett, G. Codner, M. Groves, R. Fukumura, Y. Gondo, M. Lythgoe, E. Pauws, E. Peskett, P. Stanier, L. Teboul, M. Hallegger, A. Calvo, A. Chio, A. M. Isaacs, N. L. Fawzi, E. Wang, D. E. Housman, F. Baralle, L. Greensmith, E. Buratti, V. Plagnol, E. M. Fisher, A. Acevedo-Arozena, Mice with endogenous TDP-43 mutations exhibit 
gain of splicing function and characteristics of amyotrophic lateral sclerosis. EMBO $J \mathbf{3 7}$, 10.15252/embj.201798684 (2018).

61. A. Sharma, A. K. Lyashchenko, L. Lu, S. E. Nasrabady, M. Elmaleh, M. Mendelsohn, A. Nemes, J. C. Tapia, G. Z. Mentis, N. A. Shneider, ALS-associated mutant FUS induces selective motor neuron degeneration through toxic gain of function. Nat Commun 7, 10465 (2016).

62. M. A. White, E. Kim, A. Duffy, R. Adalbert, B. U. Phillips, O. M. Peters, J. Stephenson, S. Yang, F. Massenzio, Z. Lin, S. Andrews, A. Segonds-Pichon, J. Metterville, L. M. Saksida, R. Mead, R. R. Ribchester, Y. Barhomi, T. Serre, M. P. Coleman, J. R. Fallon, T. J. Bussey, R. H. Brown, Jr., J. Sreedharan, TDP-43 gains function due to perturbed autoregulation in a Tardbp knock-in mouse model of ALS-FTD. Nature neuroscience 21, 552-563 (2018).

63. A. Devoy, R. K. Bunton-Stasyshyn, V. L. Tybulewicz, A. J. Smith, E. M. Fisher, Genomically humanized mice: technologies and promises. Nature reviews. Genetics 13, 14-20 (2011).

64. E. C. Lee, Q. Liang, H. Ali, L. Bayliss, A. Beasley, T. Bloomfield-Gerdes, L. Bonoli, R. Brown, J. Campbell, A. Carpenter, S. Chalk, A. Davis, N. England, A. Fane-Dremucheva, B. Franz, V. Germaschewski, H. Holmes, S. Holmes, I. Kirby, M. Kosmac, A. Legent, H. Lui, A. Manin, S. O'Leary, J. Paterson, R. Sciarrillo, A. Speak, D. Spensberger, L. Tuffery, N. Waddell, W. Wang, S. Wells, V. Wong, A. Wood, M. J. Owen, G. A. Friedrich, A. Bradley, Complete humanization of the mouse immunoglobulin loci enables efficient therapeutic antibody discovery. Nature biotechnology 32, 356-363 (2014).

65. T. Saito, Y. Matsuba, N. Mihira, J. Takano, P. Nilsson, S. Itohara, N. Iwata, T. C. Saido, Single App knock-in mouse models of Alzheimer's disease. Nature neuroscience 17, 661-663 (2014).

66. P. M. Nolan, A. Hugill, R. D. Cox, ENU mutagenesis in the mouse: application to human genetic disease. Briefings in functional genomics \& proteomics 1, 278-289 (2002).

67. M. A. Lewis, E. Quint, A. M. Glazier, H. Fuchs, M. H. De Angelis, C. Langford, S. van Dongen, C. Abreu-Goodger, M. Piipari, N. Redshaw, T. Dalmay, M. A. Moreno-Pelayo, A. J. Enright, K. P. Steel, An ENU-induced mutation of miR-96 associated with progressive hearing loss in mice. Nature genetics 41, 614-618 (2009).

68. A. Mencia, S. Modamio-Hoybjor, N. Redshaw, M. Morin, F. Mayo-Merino, L. Olavarrieta, L. A. Aguirre, I. del Castillo, K. P. Steel, T. Dalmay, F. Moreno, M. A. Moreno-Pelayo, Mutations in the seed region of human miR-96 are responsible for nonsyndromic progressive hearing loss. Nature genetics 41, 609-613 (2009).

69. E. M. Fisher, E. Lana-Elola, S. D. Watson, G. Vassiliou, V. L. Tybulewicz, New approaches for modelling sporadic genetic disease in the mouse. Dis Model Mech 2, 446-453 (2009).

70. T. Arbogast, A. M. Ouagazzal, C. Chevalier, M. Kopanitsa, N. Afinowi, E. Migliavacca, B. S. Cowling, M. C. Birling, M. F. Champy, A. Reymond, Y. Herault, Reciprocal Effects on Neurocognitive and Metabolic Phenotypes in Mouse Models of 16p11.2 Deletion and Duplication Syndromes. PLoS genetics 12, doi.org/10.1371/journal.pgen.1005709 (2016).

71. S. Boillee, C. Vande Velde, D. W. Cleveland, ALS: a disease of motor neurons and their nonneuronal neighbors. Neuron 52, 39-59 (2006).

72. M. H. Lee, B. Siddoway, G. E. Kaeser, I. Segota, R. Rivera, W. J. Romanow, C. S. Liu, C. Park, G. Kennedy, T. Long, J. Chun, Somatic APP gene recombination in Alzheimer's disease and normal neurons. Nature 563, 639-645 (2018).

73. E. Mass, C. E. Jacome-Galarza, T. Blank, T. Lazarov, B. H. Durham, N. Ozkaya, A. Pastore, M. Schwabenland, Y. R. Chung, M. K. Rosenblum, M. Prinz, O. Abdel-Wahab, F. Geissmann, A somatic mutation in erythro-myeloid progenitors causes neurodegenerative disease. Nature 549, 389-393 (2017).

74. K. H. Morelli, K. L. Seburn, D. G. Schroeder, E. L. Spaulding, L. A. Dionne, G. A. Cox, R. W. Burgess, Severity of Demyelinating and Axonal Neuropathy Mouse Models Is Modified by Genes Affecting Structure and Function of Peripheral Nodes. Cell reports 18, 3178-3191 (2017). 
75. Y. Shi, K. Yamada, S. A. Liddelow, S. T. Smith, L. Zhao, W. Luo, R. M. Tsai, S. Spina, L. T. Grinberg, J. C. Rojas, G. Gallardo, K. Wang, J. Roh, G. Robinson, M. B. Finn, H. Jiang, P. M. Sullivan, C. Baufeld, M. W. Wood, C. Sutphen, L. McCue, C. Xiong, J. L. Del-Aguila, J. C. Morris, C. Cruchaga, I. Alzheimer's Disease Neuroimaging, A. M. Fagan, B. L. Miller, A. L. Boxer, W. W. Seeley, O. Butovsky, B. A. Barres, S. M. Paul, D. M. Holtzman, ApoE4 markedly exacerbates tau-mediated neurodegeneration in a mouse model of tauopathy. Nature 549, 523-527 (2017).

76. F. K. Wiseman, L. J. Pulford, C. Barkus, F. Liao, E. Portelius, R. Webb, L. Chavez-Gutierrez, K. Cleverley, S. Noy, O. Sheppard, T. Collins, C. Powell, C. J. Sarell, M. Rickman, X. Choong, J. L. Tosh, C. Siganporia, H. T. Whittaker, F. Stewart, M. Szaruga, c. London Down syndrome, M. P. Murphy, K. Blennow, B. de Strooper, H. Zetterberg, D. Bannerman, D. M. Holtzman, V. L. J. Tybulewicz, E. M. C. Fisher, Trisomy of human chromosome 21 enhances amyloid-beta deposition independently of an extra copy of APP. Brain 141, 2457-2474 (2018).

77. X. J. Chen, E. N. Levedakou, K. J. Millen, R. L. Wollmann, B. Soliven, B. Popko, Proprioceptive sensory neuropathy in mice with a mutation in the cytoplasmic Dynein heavy chain 1 gene. The Journal of neuroscience : the official journal of the Society for Neuroscience 27, 1451514524 (2007).

78. H. S. Ilieva, K. Yamanaka, S. Malkmus, O. Kakinohana, T. Yaksh, M. Marsala, D. W. Cleveland, Mutant dynein (Loa) triggers proprioceptive axon loss that extends survival only in the SOD1 ALS model with highest motor neuron death. Proceedings of the National Academy of Sciences of the United States of America 105, 12599-12604 (2008).

79. D. Kieran, M. Hafezparast, S. Bohnert, J. R. Dick, J. Martin, G. Schiavo, E. M. Fisher, L. Greensmith, A mutation in dynein rescues axonal transport defects and extends the life span of ALS mice. J Cell Biol 169, 561-567 (2005).

80. M. J. Justice, P. Dhillon, Using the mouse to model human disease: increasing validity and reproducibility. Dis Mod Mechanism 9, 101-103 (2016).

81. T. F. Meehan, N. Conte, D. B. West, J. O. Jacobsen, J. Mason, J. Warren, C. K. Chen, I. Tudose, M. Relac, P. Matthews, N. Karp, L. Santos, T. Fiegel, N. Ring, H. Westerberg, S. Greenaway, D. Sneddon, H. Morgan, G. F. Codner, M. E. Stewart, J. Brown, N. Horner, C. International Mouse Phenotyping, M. Haendel, N. Washington, C. J. Mungall, C. L. Reynolds, J. Gallegos, V. GailusDurner, T. Sorg, G. Pavlovic, L. R. Bower, M. Moore, I. Morse, X. Gao, G. P. Tocchini-Valentini, Y. Obata, S. Y. Cho, J. K. Seong, J. Seavitt, A. L. Beaudet, M. E. Dickinson, Y. Herault, W. Wurst, M. H. de Angelis, K. C. K. Lloyd, A. M. Flenniken, L. M. J. Nutter, S. Newbigging, C. McKerlie, M. J. Justice, S. A. Murray, K. L. Svenson, R. E. Braun, J. K. White, A. Bradley, P. Flicek, S. Wells, W. C. Skarnes, D. J. Adams, H. Parkinson, A. M. Mallon, S. D. M. Brown, D. Smedley, Disease model discovery from 3,328 gene knockouts by The International Mouse Phenotyping Consortium. Nature genetics 49, 1231-1238 (2017).

82. J. A. Beck, S. Lloyd, M. Hafezparast, M. Lennon-Pierce, J. T. Eppig, M. F. Festing, E. M. Fisher, Genealogies of mouse inbred strains. Nature genetics 24, 23-25 (2000).

83. A. Srivastava, A. P. Morgan, M. L. Najarian, V. K. Sarsani, J. S. Sigmon, J. R. Shorter, A. Kashfeen, R. C. McMullan, L. H. Williams, P. Giusti-Rodriguez, M. T. Ferris, P. Sullivan, P. Hock, D. R. Miller, T. A. Bell, L. McMillan, G. A. Churchill, F. P. de Villena, Genomes of the Mouse Collaborative Cross. Genetics 206, 537-556 (2017).

84. S. M. Neuner, S. E. Heuer, M. J. Huentelman, K. M. S. O'Connell, C. C. Kaczorowski, Harnessing Genetic Complexity to Enhance Translatability of Alzheimer's Disease Mouse Models: A Path toward Precision Medicine. Neuron 101, 1-13 (2019).

85. S. Reardon, Lab mice's ancestral 'Eve' gets her genome sequenced. Nature 551, 281 (2017).

86. M. M. Simon, S. Greenaway, J. K. White, H. Fuchs, V. Gailus-Durner, S. Wells, T. Sorg, K. Wong, E. Bedu, E. J. Cartwright, R. Dacquin, S. Djebali, J. Estabel, J. Graw, N. J. Ingham, I. J. Jackson, A. Lengeling, S. Mandillo, J. Marvel, H. Meziane, F. Preitner, O. Puk, M. Roux, D. J. Adams, S. Atkins, A. Ayadi, L. Becker, A. Blake, D. Brooker, H. Cater, M. F. Champy, R. Combe, P. Danecek, A. di Fenza, H. Gates, A. K. Gerdin, E. Golini, J. M. Hancock, W. Hans, S. M. Holter, T. Hough, P. 
Jurdic, T. M. Keane, H. Morgan, W. Muller, F. Neff, G. Nicholson, B. Pasche, L. A. Roberson, J. Rozman, M. Sanderson, L. Santos, M. Selloum, C. Shannon, A. Southwell, G. P. TocchiniValentini, V. E. Vancollie, H. Westerberg, W. Wurst, M. Zi, B. Yalcin, R. Ramirez-Solis, K. P. Steel, A. M. Mallon, M. H. de Angelis, Y. Herault, S. D. Brown, A comparative phenotypic and genomic analysis of C57BL/6J and C57BL/6N mouse strains. Genome Biol 14, R82 (2013).

87. A. Baud, J. Flint, Identifying genes for neurobehavioural traits in rodents: progress and pitfalls. Dis Model Mech 10, 373-383 (2017).

88. N. A. Hawkins, N. J. Zachwieja, A. R. Miller, L. L. Anderson, J. A. Kearney, Fine Mapping of a Dravet Syndrome Modifier Locus on Mouse Chromosome 5 and Candidate Gene Analysis by RNA-Seq. PLoS genetics 12, e1006398 (2016).

89. L. J. Sittig, P. Carbonetto, K. A. Engel, K. S. Krauss, C. M. Barrios-Camacho, A. A. Palmer, Genetic Background Limits Generalizability of Genotype-Phenotype Relationships. Neuron 91, 12531259 (2016).

90. H. J. Han, C. C. Allen, C. M. Buchovecky, M. J. Yetman, H. A. Born, M. A. Marin, S. P. Rodgers, B. J. Song, H. C. Lu, M. J. Justice, F. J. Probst, J. L. Jankowsky, Strain background influences neurotoxicity and behavioral abnormalities in mice expressing the tetracycline transactivator. The Journal of neuroscience : the official journal of the Society for Neuroscience 32, 1057410586 (2012).

91. R. Mott, W. Yuan, P. Kaisaki, X. Gan, J. Cleak, A. Edwards, A. Baud, J. Flint, The architecture of parent-of-origin effects in mice. Cell 156, 332-342 (2014).

92. C. S. Choi, E. L. Gonzales, K. C. Kim, S. M. Yang, J. W. Kim, D. F. Mabunga, J. H. Cheong, S. H. Han, G. H. Bahn, C. Y. Shin, The transgenerational inheritance of autism-like phenotypes in mice exposed to valproic acid during pregnancy. Scientific reports 6, 36250 (2016).

93. P. Huypens, S. Sass, M. Wu, D. Dyckhoff, M. Tschop, F. Theis, S. Marschall, M. Hrabe de Angelis, J. Beckers, Epigenetic germline inheritance of diet-induced obesity and insulin resistance. Nature genetics 48, 497-499 (2016).

94. E. Hockly, B. Woodman, A. Mahal, C. M. Lewis, G. Bates, Standardization and statistical approaches to therapeutic trials in the R6/2 mouse. Brain Res Bull 61, 469-479 (2003).

95. J. P. Sundberg, P. N. Schofield, Living inside the box: environmental effects on mouse models of human disease. Dis Model Mech 11, (2018).

96. P. D. Gluckman, W. Cutfield, P. Hofman, M. A. Hanson, The fetal, neonatal, and infant environments-the long-term consequences for disease risk. Early Hum Dev 81, 51-59 (2005).

97. M. S. Oitzl, D. L. Champagne, R. van der Veen, E. R. de Kloet, Brain development under stress: hypotheses of glucocorticoid actions revisited. Neuroscience and biobehavioral reviews $\mathbf{3 4}$, 853-866 (2010).

98. E. R. Glasper, T. J. Schoenfeld, E. Gould, Adult neurogenesis: optimizing hippocampal function to suit the environment. Behav Brain Res 227, 380-383 (2012).

99. R. C. Agis-Balboa, P. S. Pinheiro, N. Rebola, C. Kerimoglu, E. Benito, M. Gertig, S. Bahari-Javan, G. Jain, S. Burkhardt, I. Delalle, A. Jatzko, M. Dettenhofer, P. A. Zunszain, A. Schmitt, P. Falkai, J. C. Pape, E. B. Binder, C. Mulle, A. Fischer, F. Sananbenesi, Formin 2 links neuropsychiatric phenotypes at young age to an increased risk for dementia. EMBO J 36, 2815-2828 (2017).

100. T. A. Bedrosian, C. Quayle, N. Novaresi, F. H. Gage, Early life experience drives structural variation of neural genomes in mice. Science (New York, N.Y.) 359, 1395-1399 (2018).

101. J. E. Kang, J. R. Cirrito, H. Dong, J. G. Csernansky, D. M. Holtzman, Acute stress increases interstitial fluid amyloid-beta via corticotropin-releasing factor and neuronal activity. Proceedings of the National Academy of Sciences of the United States of America 104, 1067310678 (2007).

102. C. Murgatroyd, A. V. Patchev, Y. Wu, V. Micale, Y. Bockmuhl, D. Fischer, F. Holsboer, C. T. Wotjak, O. F. Almeida, D. Spengler, Dynamic DNA methylation programs persistent adverse effects of early-life stress. Nature neuroscience 12, 1559-1566 (2009). 
103. C. J. Pena, H. G. Kronman, D. M. Walker, H. M. Cates, R. C. Bagot, I. Purushothaman, O. Issler, Y. E. Loh, T. Leong, D. D. Kiraly, E. Goodman, R. L. Neve, L. Shen, E. J. Nestler, Early life stress confers lifelong stress susceptibility in mice via ventral tegmental area OTX2. Science (New York, N.Y.) 356, 1185-1188 (2017).

104. M. H. Teicher, J. A. Samson, C. M. Anderson, K. Ohashi, The effects of childhood maltreatment on brain structure, function and connectivity. Nature reviews. Neuroscience 17, 652-666 (2016).

105. Y. Shin Yim, A. Park, J. Berrios, M. Lafourcade, L. M. Pascual, N. Soares, J. Yeon Kim, S. Kim, H. Kim, A. Waisman, D. R. Littman, I. R. Wickersham, M. T. Harnett, J. R. Huh, G. B. Choi, Reversing behavioural abnormalities in mice exposed to maternal inflammation. Nature 549, 482-487 (2017).

106. E. Jasarevic, C. D. Howard, K. Morrison, A. Misic, T. Weinkopff, P. Scott, C. Hunter, D. Beiting, T. L. Bale, The maternal vaginal microbiome partially mediates the effects of prenatal stress on offspring gut and hypothalamus. Nature neuroscience 21, 1061-1071 (2018).

107. N. Kulesskaya, H. Rauvala, V. Voikar, Evaluation of social and physical enrichment in modulation of behavioural phenotype in C57BL/6J female mice. PloS one 6, e24755 (2011).

108. F. Wang, H. W. Kessels, H. Hu, The mouse that roared: neural mechanisms of social hierarchy. Trends in neurosciences 37, 674-682 (2014).

109. R. Spataro, P. Volanti, D. Lo Coco, V. La Bella, Marital status is a prognostic factor in amyotrophic lateral sclerosis. Acta neurologica Scandinavica 136, 624-630 (2017).

110. A. Baud, M. K. Mulligan, F. P. Casale, J. F. Ingels, C. J. Bohl, J. Callebert, J. M. Launay, J. Krohn, A. Legarra, R. W. Williams, O. Stegle, Genetic Variation in the Social Environment Contributes to Health and Disease. PLoS genetics 13, e1006498 (2017).

111. K. M. Kokolus, M. L. Capitano, C. T. Lee, J. W. Eng, J. D. Waight, B. L. Hylander, S. Sexton, C. C. Hong, C. J. Gordon, S. I. Abrams, E. A. Repasky, Baseline tumor growth and immune control in laboratory mice are significantly influenced by subthermoneutral housing temperature. Proceedings of the National Academy of Sciences of the United States of America 110, 2017620181 (2013).

112. A. W. Fischer, B. Cannon, J. Nedergaard, Optimal housing temperatures for mice to mimic the thermal environment of humans: An experimental study. Mol Metab 7, 161-170 (2018).

113. C. Beans, What happens when lab animals go wild. Proceedings of the National Academy of Sciences of the United States of America 115, 3196-3199 (2018).

114. A. Videnovic, A. S. Lazar, R. A. Barker, S. Overeem, 'The clocks that time us'-circadian rhythms in neurodegenerative disorders. Nature Reviews Neurology 10, 683-693 (2014).

115. M. Preussner, G. Goldammer, A. Neumann, T. Haltenhof, P. Rautenstrauch, M. MullerMcNicoll, F. Heyd, Body Temperature Cycles Control Rhythmic Alternative Splicing in Mammals. Mol Cell 67, 433-446 e434 (2017).

116. M. H. Hastings, M. Goedert, Circadian clocks and neurodegenerative diseases: time to aggregate? Current opinion in neurobiology 23, 880-887 (2013).

117. J. J. lliff, M. Wang, Y. Liao, B. A. Plogg, W. Peng, G. A. Gundersen, H. Benveniste, G. E. Vates, R. Deane, S. A. Goldman, E. A. Nagelhus, M. Nedergaard, A paravascular pathway facilitates CSF flow through the brain parenchyma and the clearance of interstitial solutes, including amyloid beta. Science translational medicine 4, 147ra111 (2012).

118. E. S. Musiek, D. M. Holtzman, Mechanisms linking circadian clocks, sleep, and neurodegeneration. Science (New York, N.Y.) 354, 1004-1008 (2016).

119. V. Vyazovskiy, Walton, M.E., Peirson, S.N., Bannerman, D.M., Sleep homeostasis, habits and habituation. Current opinion in neurobiology 44, 202-211 (2017).

120. C. D. Wrann, J. P. White, J. Salogiannnis, D. Laznik-Bogoslavski, J. Wu, D. Ma, J. D. Lin, M. E. Greenberg, B. M. Spiegelman, Exercise induces hippocampal BDNF through a PGC1alpha/FNDC5 pathway. Cell Metab 18, 649-659 (2013). 
121. H. van Praag, B. R. Christie, T. J. Sejnowski, F. H. Gage, Running enhances neurogenesis, learning, and long-term potentiation in mice. Proceedings of the National Academy of Sciences of the United States of America 96, 13427-13431 (1999).

122. H. van Praag, G. Kempermann, F. H. Gage, Running increases cell proliferation and neurogenesis in the adult mouse dentate gyrus. Nature neuroscience 2, 266-270 (1999).

123. H. van Praag, T. Shubert, C. Zhao, F. H. Gage, Exercise enhances learning and hippocampal neurogenesis in aged mice. The Journal of neuroscience : the official journal of the Society for Neuroscience 25, 8680-8685 (2005).

124. S. von Holstein-Rathlou, N. C. Petersen, M. Nedergaard, Voluntary running enhances glymphatic influx in awake behaving, young mice. Neurosci Lett 662, 253-258 (2018).

125. E. Hockly, P. M. Cordery, B. Woodman, A. Mahal, A. van Dellen, C. Blakemore, C. M. Lewis, A. J. Hannan, G. P. Bates, Environmental enrichment slows disease progression in R6/2 Huntington's disease mice. Annals of neurology 51, 235-242 (2002).

126. A. van Dellen, C. Blakemore, R. Deacon, D. York, A. J. Hannan, Delaying the onset of Huntington's in mice. Nature 404, 721-722 (2000).

127. D. Ferreira, A. Machado, Y. Molina, A. Nieto, R. Correia, E. Westman, J. Barroso, Cognitive Variability during Middle-Age: Possible Association with Neurodegeneration and Cognitive Reserve. Front Aging Neurosci 9, 188 (2017).

128. K. Yamamoto, S. E, Y. Hatakeyama, Y. Sakamoto, T. Honma, Y. Jibu, Y. Kawakami, T. Tsuduki, The Japanese diet from 1975 delays senescence and prolongs life span in SAMP8 mice. Nutrition 32, 122-128 (2016).

129. M. N. Jensen, M. Ritskes-Hoitinga, How isoflavone levels in common rodent diets can interfere with the value of animal models and with experimental results. Laboratory animals 41, 1-18 (2007).

130. J. P. K. Rooney, A. E. Visser, F. D'Ovidio, R. Vermeulen, E. Beghi, A. Chio, J. H. Veldink, G. Logroscino, L. H. van den Berg, O. Hardiman, M. C. Euro, A case-control study of hormonal exposures as etiologic factors for ALS in women: Euro-MOTOR. Neurology 89, 1283-1290 (2017).

131. S. Kim, H. Kim, Y. S. Yim, S. Ha, K. Atarashi, T. G. Tan, R. S. Longman, K. Honda, D. R. Littman, G. B. Choi, J. R. Huh, Maternal gut bacteria promote neurodevelopmental abnormalities in mouse offspring. Nature 549, 528-532 (2017).

132. E. Sherwin, T. G. Dinan, J. F. Cryan, Recent developments in understanding the role of the gut microbiota in brain health and disease. Ann N Y Acad Sci, (2017).

133. S. P. Rosshart, B. G. Vassallo, D. Angeletti, D. S. Hutchinson, A. P. Morgan, K. Takeda, H. D. Hickman, J. A. McCulloch, J. H. Badger, N. J. Ajami, G. Trinchieri, F. Pardo-Manuel de Villena, J. W. Yewdell, B. Rehermann, Wild Mouse Gut Microbiota Promotes Host Fitness and Improves Disease Resistance. Cell 171, 1015-1028 e1013 (2017).

134. T. R. Sampson, J. W. Debelius, T. Thron, S. Janssen, G. G. Shastri, Z. E. Ilhan, C. Challis, C. E. Schretter, S. Rocha, V. Gradinaru, M. F. Chesselet, A. Keshavarzian, K. M. Shannon, R. Krajmalnik-Brown, P. Wittung-Stafshede, R. Knight, S. K. Mazmanian, Gut Microbiota Regulate Motor Deficits and Neuroinflammation in a Model of Parkinson's Disease. Cell 167, 1469-1480 (2016).

135. M. Sgritta, S. W. Dooling, S. A. Buffington, E. N. Momin, M. B. Francis, R. A. Britton, M. CostaMattioli, Mechanisms Underlying Microbial-Mediated Changes in Social Behavior in Mouse Models of Autism Spectrum Disorder. Neuron 101, 246-259 e246 (2019).

136. L. K. Beura, S. E. Hamilton, K. Bi, J. M. Schenkel, O. A. Odumade, K. A. Casey, E. A. Thompson, K. A. Fraser, P. C. Rosato, A. Filali-Mouhim, R. P. Sekaly, M. K. Jenkins, V. Vezys, W. N. Haining, S. C. Jameson, D. Masopust, Normalizing the environment recapitulates adult human immune traits in laboratory mice. Nature 532, 512-516 (2016).

137. R. M. Ransohoff, How neuroinflammation contributes to neurodegeneration. Science (New York, N.Y.) 353, 777-783 (2016). 
138. C. Cunningham, Microglia and neurodegeneration: the role of systemic inflammation. Glia 61, 71-90 (2013).

139. R. S. Klein, C. Garber, N. Howard, Infectious immunity in the central nervous system and brain function. Nat Immunol 18, 132-141 (2017).

140. S. P. Sri, C.-M.; Cave, C.A.; Hough, K.; Wood, N.; Gomez-Nicola, D.; Deinhardt, K.; Bannerman, D.; Perry, H.V.; Vargas-Caballero, M., Emergence of synaptic and cognitive impairment in a mature-onset APP mouse model of Alzheimer's Disease. Acta neuropathologica communications in press, (2019).

141. D. J. Sanderson, D. M. Bannerman, The role of habituation in hippocampus-dependent spatial working memory tasks: evidence from GluA1 AMPA receptor subunit knockout mice. Hippocampus 22, 981-994 (2012).

142. D. Pritchett, A. M. Taylor, C. Barkus, S. J. Engle, N. J. Brandon, T. Sharp, R. G. Foster, P. J. Harrison, S. N. Peirson, D. M. Bannerman, Searching for cognitive enhancement in the Morris water maze: better and worse performance in D-amino acid oxidase knockout (Dao(-/-)) mice. Eur J Neurosci 43, 979-989 (2016).

143. M. H. Huisman, M. Seelen, P. T. van Doormaal, S. W. de Jong, J. H. de Vries, A. J. van der Kooi, M. de Visser, H. J. Schelhaas, L. H. van den Berg, J. H. Veldink, Effect of Presymptomatic Body Mass Index and Consumption of Fat and Alcohol on Amyotrophic Lateral Sclerosis. JAMA Neurol 72, 1155-1162 (2015).

144. M. Enserink, Sloppy reporting on animal studies proves hard to change. Science (New York, N.Y.) 357, 1337-1338 (2017).

145. D. W. Howells, E. S. Sena, M. R. Macleod, Bringing rigour to translational medicine. Nature reviews. Neurology 10, 37-43 (2014).

146. C. Kilkenny, W. J. Browne, I. C. Cuthill, M. Emerson, D. G. Altman, Improving bioscience research reporting: the ARRIVE guidelines for reporting animal research. PLOS Biol 8, e1000412 (2010).

147. S. Perrin, Preclinical research: Make mouse studies work. Nature 507, 423-425 (2014).

148. J. M. Keil, J. Seo, M. D. Howell, W. H. Hsu, R. N. Singh, C. J. DiDonato, A short antisense oligonucleotide ameliorates symptoms of severe mouse models of spinal muscular atrophy. Mol Ther Nucleic Acids 3, e174 (2014).

149. M. C. Birling, Y. Herault, G. Pavlovic, Modeling human disease in rodents by CRISPR/Cas9 genome editing. Mamm Genome 28, 291-301 (2017).

150. J. Nicod, R. W. Davies, N. Cai, C. Hassett, L. Goodstadt, C. Cosgrove, B. K. Yee, V. Lionikaite, R. E. McIntyre, C. A. Remme, E. M. Lodder, J. S. Gregory, T. Hough, R. Joynson, H. Phelps, B. Nell, C. Rowe, J. Wood, A. Walling, N. Bopp, A. Bhomra, P. Hernandez-Pliego, J. Callebert, R. M. Aspden, N. P. Talbot, P. A. Robbins, M. Harrison, M. Fray, J. M. Launay, Y. M. Pinto, D. A. Blizard, C. R. Bezzina, D. J. Adams, P. Franken, T. Weaver, S. Wells, S. D. M. Brown, P. K. Potter, P. Klenerman, A. Lionikas, R. Mott, J. Flint, Genome-wide association of multiple complex traits in outbred mice by ultra-low-coverage sequencing. Nature genetics 48, 912-918 (2016).

151. R. Chia, F. Achilli, M. F. W. Festing, E. M. C. Fisher, The origins and uses of mouse outbred stocks. Nature genetics 37, 1181-1186 (2005).

152. J. Cooper-Knock, H. Robins, I. Niedermoser, M. Wyles, P. R. Heath, A. Higginbottom, T. Walsh, M. Kazoka, E. A. L. S. S. C. Project Min, P. G. Ince, G. M. Hautbergue, C. J. McDermott, J. Kirby, P. J. Shaw, Targeted Genetic Screen in Amyotrophic Lateral Sclerosis Reveals Novel Genetic Variants with Synergistic Effect on Clinical Phenotype. Front Mol Neurosci 10, 370 (2017).

153. K. J. Egan, H. M. Vesterinen, V. Beglopoulos, E. S. Sena, M. R. Macleod, From a mouse: systematic analysis reveals limitations of experiments testing interventions in Alzheimer's disease mouse models. Evid Based Preclin Med 3, e00015 (2016).

154. S. Scott, J. E. Kranz, J. Cole, J. M. Lincecum, K. Thompson, N. Kelly, A. Bostrom, J. Theodoss, B. M. Al-Nakhala, F. G. Vieira, J. Ramasubbu, J. A. Heywood, Design, power, and interpretation of studies in the standard murine model of ALS. Amyotroph Lateral Scler 9, 4-15 (2008). 
155. R. S. Bains, H. L. Cater, R. R. Sillito, A. Chartsias, D. Sneddon, D. Concas, P. Keskivali-Bond, T. C. Lukins, S. Wells, A. Acevedo Arozena, P. M. Nolan, J. D. Armstrong, Analysis of Individual Mouse Activity in Group Housed Animals of Different Inbred Strains using a Novel Automated Home Cage Analysis System. Front Behav Neurosci 10, 106 (2016).

156. L. R. Glover, T. J. Schoenfeld, R. M. Karlsson, D. M. Bannerman, H. A. Cameron, Ongoing neurogenesis in the adult dentate gyrus mediates behavioral responses to ambiguous threat cues. PLoS Biol 15, e2001154 (2017). 
Fig. 1. Examples of differences in human and mouse genetic loci that may affect how we model neurodegeneration.

Humans and mice are separated by only 75 million years of evolution. Genetic differences that give rise to neurodegeneration in humans but are not found in mice, include human or primate specific repeat sequences that may mutate a gene giving a human disease such as the 'SVA' repeats (red box) that have inserted into the intron of the FUKUTIN and the TAF1 genes, giving Fukuyama muscular dystrophy and X-linked Dystonia Parkinsonism, respectively (exons shown as grey boxes) $(23,24)$. Gene regulation may be different, for example, as in OSTEOCRIN which is expressed in the human but not mouse nervous system because primates have acquired an enhancer (red box) leading to neuronal expression (21). Splicing patterns may be different between human and mouse as occurs in normal expression of the TAU mRNA and protein (20) or abnormal expression of STATHMIN2 in ALS (26). Gene copy number can be different between the two species, as with the single Smn gene found in mouse and its paralogous SMN1 and SMN2 genes in humans that when mutated give rise to SMA (11). Mouse genes are arranged over 19 autosomes and 2 sex chromosomes, and human genes lie within 22 autosomes and 2 sex chromosomes, such that the most common genetic form of cognitive disability, Down's syndrome which arises from trisomy 21 , must be modelled either by creating an animal with the human (7) chromosome or by chromosome engineering duplications in the three mouse chromosomes $(10,17,16)$ with regions of homology to human chromosome 21 (8). At a population level we usually study inbred strains of mice, which are genetically homogenous, compared with human populations which are genetically diverse. 


\section{Fig. 3. Behavioral tests for mouse models of neurodegeneration.}

(A) In the Morris watermaze test (top panel) rodents are trained to find a hidden escape platform that is submerged $1-2 \mathrm{~cm}$ below the surface of the water (left) but that remains in the same spatial location relative to external cues. There are difficulties associated with testing mice in this watermaze task such as thigmotaxis, floating behavior and fatigue following prolonged swim times, all of which are often more pronounced in genetically modified animals. The question is whether impairments in watermaze performance in some mouse models of neurodegenerative disorders genuinely reflect deficits in learning and memory that the water maze test is supposed to measure. (B) Spatial working memory in rodents is tested using a radial maze or T-maze, but these tests may not equate to tests used in humans to measure working memory such as the N-back or digit span tasks. In the T-maze task, during the sample run (left ) the rodent is forced into one of the two arms of the maze to obtain a food reward. After a short delay, the animal is then given a choice between both arms of the maze and must go to the previously unvisited arm to gain a second reward (choice run; right). (C) Contextual fear conditioning in rodents is often used to test hippocampus-dependent, rapid, one trial, episodiclike memory. In this task, rodents are placed in a novel chamber and receive a mild footshock. The rodent is then later returned to the chamber and the amount of freezing behavior that the animal exhibits is taken as a measure of how much it has learned about the context-shock association. 